\title{
Grupos locales, acceso al agua y su problemática de contaminación en la ciénega de Chapala, Michoacán
}

\section{Local groups, access to water and the pollution problem of Chapala marsh, Michoacan}

\author{
Adriana Sandoval-Moreno \\ María Antonieta OchoA-Ocaña*
}

\begin{abstract}
This paper approaches the problem of local groups in respect to water access and its pollution in Chapala marsh in Michoacan; the cases of agriculturists, fishermen and inhabitants of the population centers are exposed, which share the land, face disjunctives to access water and the implications in the development of their activities from the use of polluted water. Before this situation, several of these groups perform short-reach, not integral, actions with the sole end of providing themselves with water; these conditions might deepen the problem rather than lead to sustainable water management in the region
\end{abstract}

Keywords: local groups, marsh, Chapala, water, pollution.

\section{Resumen}

El presente texto aborda la problemática de los grupos locales respecto al acceso al agua y su contaminación en la ciénega de Chapala michoacana. Se exponen los casos de los grupos de agricultores, pescadores y habitantes de los centros poblacionales, los cuales comparten el territorio, enfrentan disyuntivas para acceder al agua y las implicaciones en el desarrollo de sus actividades por el uso de agua contaminada. Ante esta situación, varios de estos grupos llevan a cabo acciones de corto alcance, no integrales, con el único objetivo de abastecerse del vital líquido, condiciones que pueden profundizar el problema, más que conducir a un manejo sustentable del agua en la región.

Palabras clave: grupos locales, ciénega, Chapala, agua, contaminación.

* Universidad Nacional Autónoma de México, México. Correos-e: coraliaz@yahoo.com, asandoval@humanidades.unam.mx, antonietao@hotmail.com. 


\section{Introducción}

A partir de una escala macrorregional, la región hidrológica Lerma-Santiago-Pacífico se ubica en la franja central del país, la más poblada. En ella están comprendidos parte de los estados de Guanajuato, Jalisco, Estado de México, Michoacán y Querétaro, con una superficie total de $51,887 \mathrm{~km}^{2}$, considerando las cuencas cerradas de Pátzcuaro y Cuitzeo; la superficie de la cuenca principal o interconectada es de $47,116 \mathrm{~km}^{2}$ (Semarnat, 2006). En la escala mezo, la zona hidrológica río LermaChapala pertenece al curso del río Lerma, ${ }^{1}$ su principal afluente, y se caracteriza por enfrentar problemas de disponibilidad de agua que alcanza proporciones críticas, debido sobre todo a las derivaciones de caudales con fines agrícolas y ciudades como Guadalajara.

En la escala micro se localiza la ciénega de Chapala, la cual pertenece al estado de Jalisco por el lado norte del lago de Chapala, y por el sureste al estado de Michoacán.

La ciénega de Chapala es la fracción territorial final de la cuenca Lerma-Chapala y es ejemplo de la desconexión entre las personas que contaminan aguas arriba, y quienes sufren los efectos de la contaminación en los flujos descendentes de la cuenca, los cuales desembocan en el lago de Chapala. Contaminación que imprime un desequilibrio en los ecosistemas, favorecido por las prácticas agrícolas con el empleo de agrotóxicos y la falta de saneamiento de las aguas residuales municipales, que hacen un panorama costoso en la Ciénega en cuestión de saneamiento y abasto de agua para los diferentes usos.

El lago de Chapala es el cuerpo receptor del largo recorrido del agua por el río Lerma. Según el Consejo de Cuenca Lerma Chapala: "[en la cuenca] no existe disponibilidad de agua superficial y su calidad se ha deteriorado significativamente, lo que repercute en el desempeño de las actividades económicas de la región y en los acuíferos" (Boletín, 2008). También en el agua subterránea del acuífero 1607 "Ciénega de Chapala" hay un déficit de disponibilidad, por lo que no existe volumen disponible para nuevas concesiones (Conagua, 2002). Al mismo tiempo, porque la ciénega se ubica en la franja de sequía extrema, el mes de mayo es el más significativo, las afectaciones por el cambio climático hacen más vulnerable la zona (Conagua, 2008). Al respecto, la referencia de crisis más

${ }^{1}$ El río Lerma funciona como el colector principal con una longitud aproximada de $705 \mathrm{~km}$; en su recorrido se integran como tributarios principales los ríos La Gavia, Jaltepec, Laja, Silao, Guanajuato, Turbio, Angulo y Duero, que descargan al final en el lago de Chapala; este vaso natural interior es el de mayor dimensión del país y donde también descargan los ríos La Pasión y Zula (Conagua, 2003). 


\section{Mapa I \\ Ciénega de Chapala jalisciense y michoacana}

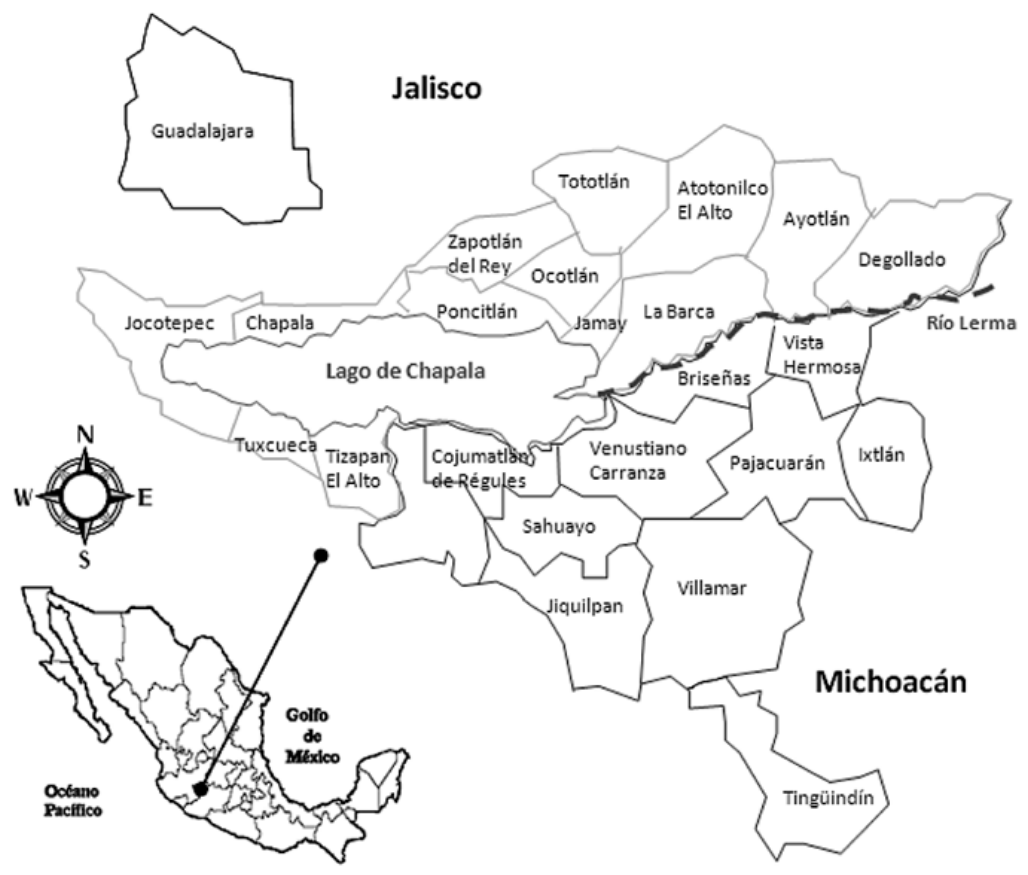

Fuente: Elaboración propia.

grande de sequía que ha sufrido el lago de Chapala, es el año 1945, cuyo desecamiento duró hasta 1957 (Boehm, 2002).

Estas condiciones ambientales han impulsado numerosos estudios acerca de la cuenca Lerma-Chapala y del lago de Chapala, en especial de la porción jalisciense ${ }^{2}$ (Paré, 1989; Hernández, 2000; Valdez y Arroyo, 2000; Valdez et al., 2000; Hansen y Van Afferden, 2001; Gómez-Reyna, 2007). Se pueden identificar investigaciones que abordan la problemática demográfica y la presión en los recursos hídricos por parte de los usuarios del agua en la cuenca Lerma-Chapala (Burton, 1997; Barragán et al., 2004; Caire, 2005; Conagua, 2002; Duran et al., 2005; entre otros). Sin embargo, los estudios con enfoque social son los menos, y los existentes abordan el problema hídrico desde la configuración sociohistórica

${ }^{2}$ Los pescadores de Chapala y la defensa de su lago, investigación realizada por diversas instituciones, UNAM, ITESO y El Colegio de Jalisco entre 1984 y 1986, coordinado por Luisa Paré, estudios realizados por el Instituto Mexicano de Tecnología del Agua (Hansen y Van Afferden) en el 2001 y el estudio coordinado por el doctor López-Reyna y colaboradores del Centro de Ciencias Exactas de la Universidad de Guadalajara. 
y regional. Aquí sobresalen los estudios de El Colegio de Michoacán en la ciénega (Boehm, 2001, 2005), también destacan los trabajos sobre el uso y manejo del agua en términos históricos (Tortolero, 2002; Peña, 2005; Aboites, 2002; entre otros). Sobre el asunto de gestión y conflicto sobresalen los de la cuenca Lerma-Chapala (Tortajada, 2002; Ávila García, 2002, y otros). Sin embargo, hay una ausencia de estudios holísticos para la región ciénega de Chapala que integren la perspectiva social y ambiental en las dinámicas de acceso y control de los recursos hídricos por los grupos locales, que den cuenta de las condiciones y arreglos para desarrollar sus formas de vida en el territorio, además de sus actividades de producción, como la pesca y la agricultura.

Aún falta profundizar en el análisis de la actuación de los grupos locales y el acceso a los recursos hídricos, sobre todo cuando se considera el agua un bien escaso y un derecho para la supervivencia humana. Hasta ahora, las investigaciones de la ciénega de Chapala son discontinuas y fragmentadas en el análisis territorial, en especial ha sido menos estudiada la ciénega michoacana; por lo que es necesario generar información suficiente y actualizada, que permita dilucidar los procesos y sus cambios a lo largo del tiempo y del espacio. Esto requiere, además, trabajar en forma coordinada entre grupos de investigación, asociaciones civiles y el sector gubernamental en sus tres niveles.

Este texto es producto de dos investigaciones llevadas a cabo en la Unidad Académica de Estudios Regionales de la Coordinación de Humanidades de la UNAM; una investigación indaga sobre las estrategias de los grupos locales en el manejo de los recursos hídricos y otra estudia la calidad de vida en las localidades, ambas en la ciénega de Chapala. El objeto de este trabajo es exponer los casos de los grupos de agricultores, pescadores y habitantes de los centros poblacionales que comparten el territorio, enfrentan disyuntivas para acceder al agua y las implicaciones en el desarrollo de sus actividades por el uso de agua contaminada. Ante esta situación, varios de estos grupos están llevando a cabo acciones de corto alcance, no integrales, con el único objetivo de abastecerse del vital líquido, condiciones que puede profundizar la problemática, más que conducir a un manejo sustentable del agua en la región.

En el texto se abordan los siguientes cuestionamientos: ¿cómo afecta a grupos de agricultores, pescadores y habitantes de los centros poblacionales de la ciénega michoacana el deterioro en la calidad y la baja disponibilidad del agua?, ¿`cuáles son las respuestas de dichos grupos al verse afectados en sus actividades productivas y reproductivas?, ¿'son estas respuestas evidencia de una alternativa de manejo sustentable del agua en la región?

Para responder a estas preguntas, se tomó como premisa que las modificaciones humanas en detrimento de los sistemas de agua y los cambios 
en el uso del suelo tienen efectos adversos en la calidad del agua superficial y subterránea, que a su vez tiene efectos negativos en la salud humana, el ecosistema y las actividades que dependen de los recursos naturales en el territorio. Así, se procedió a identificar los grupos de individuos involucrados en el manejo de agua para los usos detectados en la ciénega de Chapala michoacana, ${ }^{3}$ luego se indagó sobre el manejo de agua ${ }^{4}$ en relación con la disminución de la calidad del agua y se analizaron las afectaciones a las actividades que llevan a cabo y las respuestas de estos grupos de personas.

El texto se divide en tres partes. En la primera se describen las condiciones generales de la ciénega de Chapala para dar cuenta del contexto en que se desarrollan las actividades de los actores locales de estudio. En la segunda parte se abordan las disyuntivas de los grupos locales (agricultores, pescadores y consumidores de agua potable) en el acceso al agua superficial y subterránea, los problemas generados por la escasez y la contaminación del agua, y se describen las principales estrategias socioculturales, productivas y de consumo. En la tercera se presentan las conclusiones generales y lo endeble de las condiciones de los recursos hídricos para tener un manejo sustentable de los mismos.

\section{La ciénega de Chapala}

Se ubica al oriente del lago de Chapala, es un área compartida por los estados de Jalisco y Michoacán, y la constituyen los municipios de Jamay, Ocotlán, Poncitlán, Chapala, Jocotepec, Tuxcueca y Tizapán en Jalisco; y Cojumatlán de Régules, Venustiano Carranza, Briseñas, Jiquilpan, Sahuayo, Venustiano Carranza y Villamar en Michoacán.

Históricamente la cuenca del lago de Chapala era un área de alrededor de 150,000 ha. Su espejo de agua año con año crecía en los periodos de lluvia y decrecía en octubre y noviembre. Cuando empezaba a bajar el agua, emergían pequeñas porciones húmedas con una riqueza mineral que permitía cosechas abundantes de cultivos de maíz y garbanzo, además de ricos pastos para el ganado (Moreno, 1988: 14; Boehm, 2002).

La estructura e infraestructura urbanas de los pueblos indígenas establecidos en la ciénaga, fue la expresión formal de las condiciones naturales del lugar, al diseñar un sistema de comunicación por medio de puentes que les permitía desplazarse y aprovechar las condiciones de humedad.

\footnotetext{
${ }^{3}$ Para más información, véase la Ley de Aguas Nacionales y su Reglamento (2004), artículo 3, sobre los tipos de uso: agrícola, doméstico, en acuacultura, pecuario y público urbano.

${ }^{4}$ Se entiende por manejo de agua cualquier modo de uso mediante los recursos de conocimiento, tecnologías, instrumentos, bienes, derechos de acceso formales y no formales, y atribuciones disponibles, sea de una persona o de un grupo.
} 


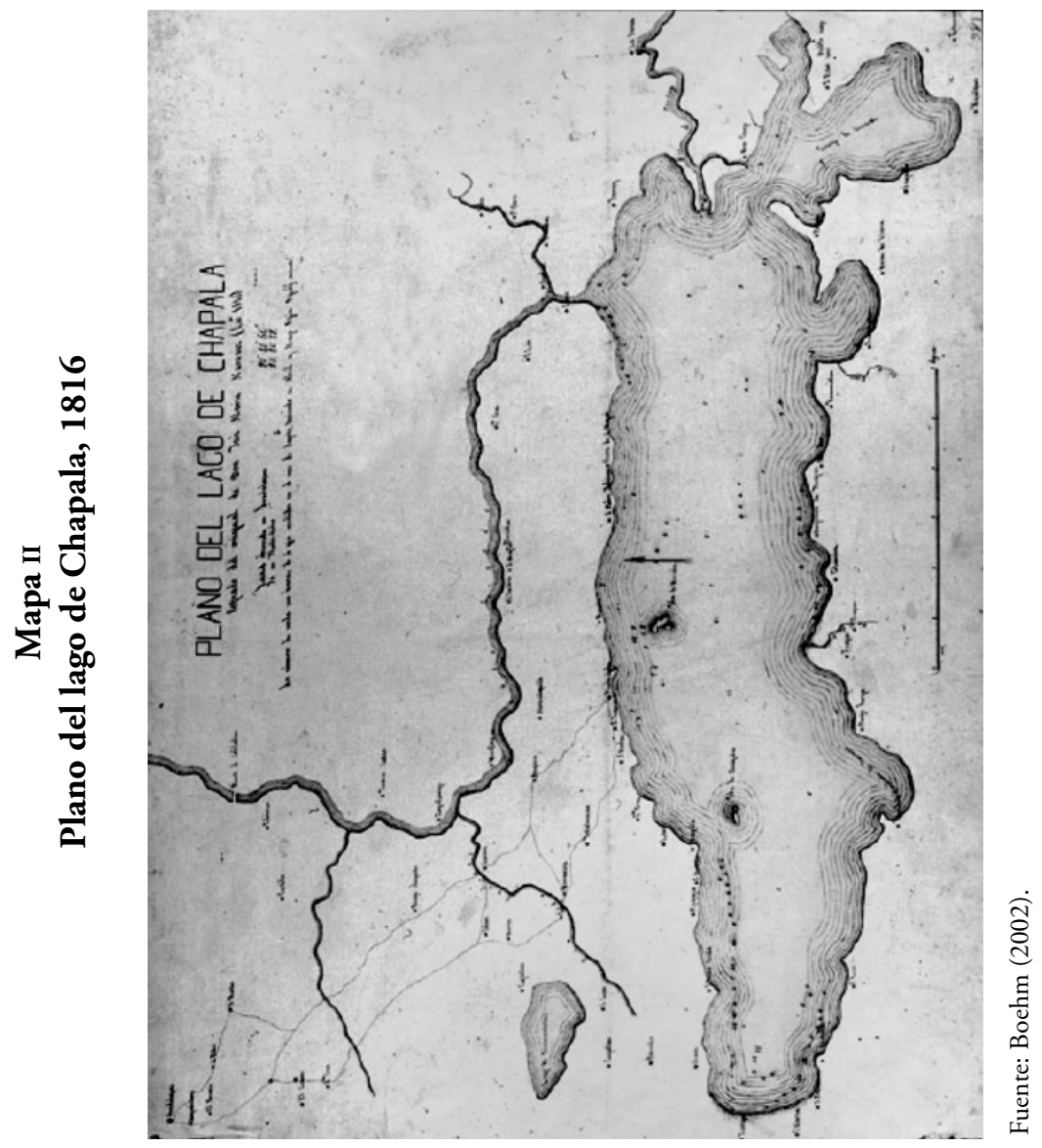




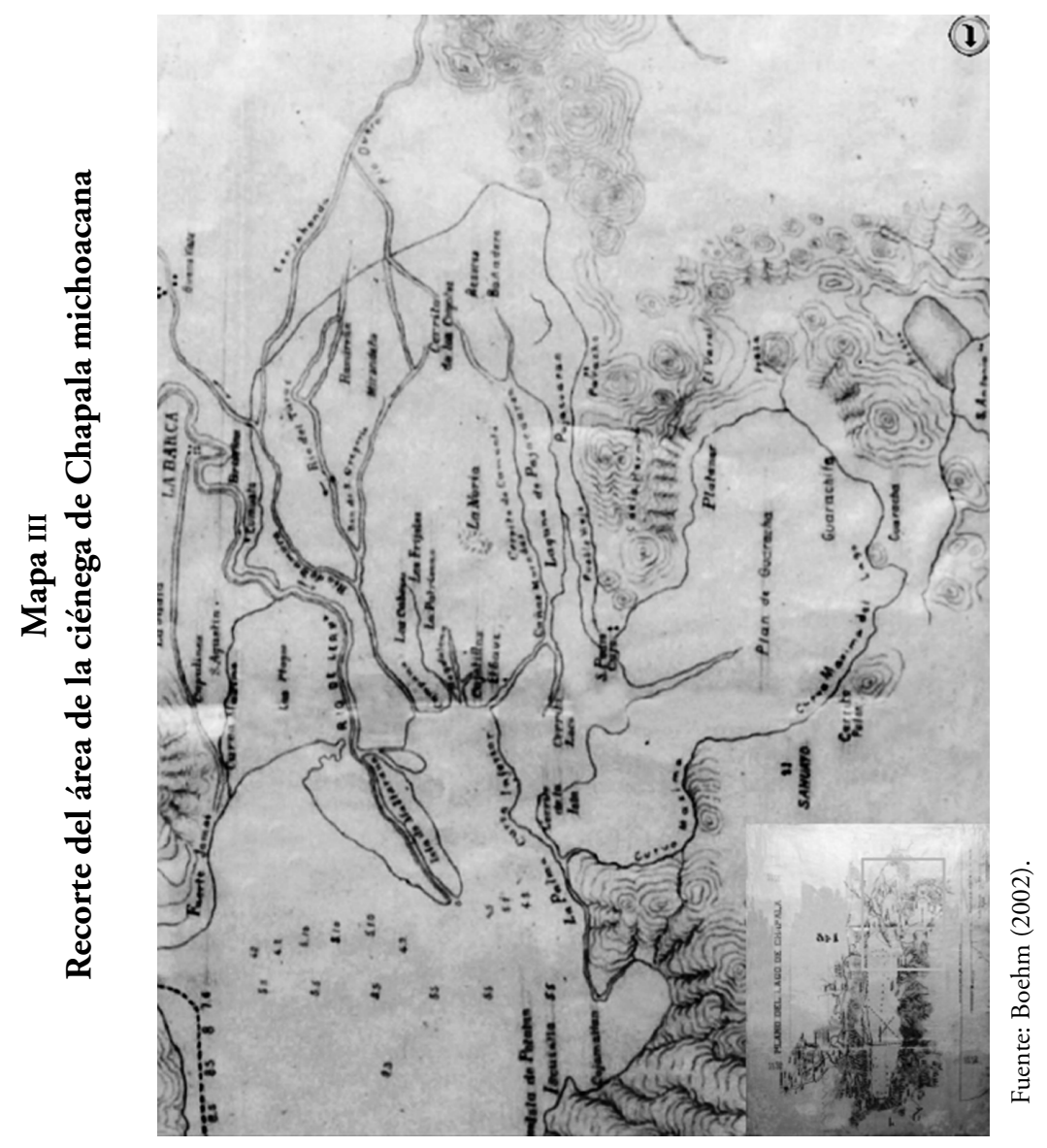


La actividad pesquera era común entre los pueblos situados en la ribera del lago, mientras que en los pequeños asentamientos humanos las actividades agrícolas complementaban la dieta diaria abundante en carne y pescado (Covarruvias et al., 2008). Con el dominio español, los poblados de la región pronto fueron sometidos al control de la Colonia y grandes extensiones de tierra se las apropiaron familias que aprovechaban las ciénagas para agostar el ganado, sobre todo en la temporada de secas, además de gozar del servicio personal de los naturales (Ochoa, 2003: 47).

Ante esta abundancia, en el siglo xx la ciénega también fue atractiva para los grandes terratenientes, como Manuel Cuesta Gallardo, gobernador del estado de Jalisco (1911), quien con fines comerciales al vislumbrar el potencial productivo de la zona, propuso al presidente Porfirio Díaz desecar los terrenos del lado sureste del lago, mediante la construcción de un bordo. Así, entre 1904 y 1908 se realizó la obra civil del bordo de contención de Maltaraña, para desecar $560 \mathrm{~km}^{2}$ en los límites de Jalisco y Michoacán, y formar lo que hoy se conoce como ciénega de Chapala, una planicie de aproximadamente 80,000 ha (Guzmán et al., 2001; Boehm, 2002).

Las nuevas tierras se convirtieron en fuente segura para establecer viviendas y para actividades productivas, como la agricultura y la ganadería, pero se redujo la actividad pesquera en el lado michoacano, al limitarse a las poblaciones ribereñas de Petatán, La Palma, El Puerto de León, Rincón de María, Cojumatlán, La Puntita y La Puerta. Las tierras desecadas constituyeron después una región importante de riego, al establecerse el Distrito de Riego 024 Ciénega de Chapala, el cual comenzó a operar en el año 1936, orientado originalmente a la producción de granos básicos y en los últimos tiempos también al sorgo, cártamo y hortalizas, entre otros.

En el plano socioorganizacional, para los campesinos de la región los primeros años como ejidatarios no fueron fáciles, pues al estar desprovistos de aperos y animales de trabajo, fueron presa fácil de los usureros locales y clientela segura de los incipientes caciques, que pronto se convirtieron en intermediarios en las gestiones por el agua, los créditos y las titulaciones ante el gobierno federal y estatal. Entre industriales, comerciantes, profesionistas y agricultores, pequeńos propietarios y líderes ejidatarios comenzaron a conformarse las nuevas oligarquías regionales que reemplazaron a los antiguos terratenientes y arrendatarios (Boehm, 2002).

En cuanto a los centros poblacionales, a partir de mediados del siglo xx la ciénega de Chapala responde a la misma lógica de la cuenca LermaChapala a la que pertenece, con una tendencia incremental de su población, espacios urbanos y un notable deterioro ambiental. El río Lerma es uno de los principales contribuyentes al lago: nace en el Estado de México y en sus aguas se vierten aguas residuales tratadas $-\mathrm{y}$ sin tratar- de 
centros industriales y urbanos, además del arrastre de agroquímicos empleados en la agricultura, aguas que finalmente desembocan en el lago de Chapala, favoreciendo con esto el deterioro gradual del mismo (Semarnat, 2006). Por otro lado, la ciénega de Chapala es un territorio inundable, donde las obras civiles no han podido controlar del todo el agua, ya que año con año se presentan problemas de inundación en las partes bajas, afectando zonas pobladas y de cultivo, lo que significa pérdidas materiales y económicas.

La situación del lago de Chapala se tornó alarmante cuando en 1945 se presentó una pronunciada sequía que duró hasta 1957, estimulando otra obra de comunicación del río Lerma con otro de los ríos más importantes en toda la cuenca: el Santiago, desde Maltaraña hasta Ocotlán, mediante la construcción de un canal que recibió el nombre del ingeniero Ballesteros. Estas acciones han tenido implicaciones a largo plazo al afectar el equilibrio hidrológico en toda la cuenca (Boehm, 2002). La región ciénega de Chapala ha sufrido cambios ambientales profundos, ya que todavía a principios del siglo xx la economía de las comunidades asentadas en su ribera no estaba basada en la agricultura (Covarrubias et al., 2008); mientras que en las tierras anegadas y sus islas, la vida productiva estaba sujeta a los ritmos de la naturaleza: en las crecidas de agua se llevaban a cabo actividades lacustres (pesca y fabricación de cestas con los carrizos y tules) y en la época de secas los pastos servían de alimento al ganado (Moreno, 1989).

En el lago de Chapala, el bajo volumen de agua ha traído cambios adversos en la profundidad, grados de temperatura y la transparencia. Así, el lago presenta problemas en su sistema hidrológico por la desecación o pérdida de la superficie lacustre, por insuficiencia de aportes respecto del volumen extraído, azolvamiento, contaminación y graves efectos en las poblaciones que habitan en este ecosistema.

En suma, con la política gubernamental de aprovechamiento de agua, la construcción del bordo de Maltaraña y la ampliación de la frontera agrícola de forma permanente, el paisaje y las dinámicas de su población cambiaron, marcando un parteaguas en 1910, antes y después de las obras de aprovechamiento de agua y suelo, lo que contribuyó al problema del crecimiento desordenado de las ciudades, que exigía el incremento de la demanda de agua, provocando la sobreexplotación del acuífero y la presencia de contaminantes por la falta de tratamiento de aguas residuales, ${ }^{5}$

\footnotetext{
${ }^{5}$ El modelo económico de la década de los cuarenta se basó en el crecimiento y concentración urbano-industrial, y ciudades como la de México, Guadalajara y Monterrey se convirtieron en los principales ejes de crecimiento del país, en tanto las zonas rurales aportaron alimentos baratos, materias primas y mano de obra para la producción manufactura industrial; lo anterior apoyado por políticas agrarias, agrícolas, infraestructura hidráulica y paquetes tecnológicos.
} 


\section{Esquema I}

\section{Contaminación del río Lerma}

\begin{tabular}{ll}
\hline \multicolumn{1}{c}{ Bacteriológica } & \multicolumn{1}{c}{ Química } \\
\hline $\begin{array}{l}\text { Descargas urbanas del Estado } \\
\text { de México, Querétaro, } \\
\text { Guanajuato y Michoacán }\end{array}$ & $\begin{array}{l}\text { Descargas residuales de parques industriales de las } \\
\text { ramas química, textil, metalmecánica, cervecera, } \\
\text { cementera, automotriz, termoeléctrica y porcícola }\end{array}$ \\
$\begin{array}{l}\text { Presencia de coliformes* } \\
\text { Grasas y aceites, metales pesados, detergentes, } \\
\text { compuestos orgánicos y agroquímicos }\end{array}$ \\
\hline
\end{tabular}

Fuente: Elaboración propia.

*118/1000 ml centro lago; 7500/1000 ml ribera y más de 10,000/1000 ml en desembocadura del río Lerma en el lago (U. de G., citado por Paré, 1989). Los coliformes son microorganismos presentes en aguas residuales de asentamientos humanos, básicamente asociados a desechos fecales, y que al ser el hombre hospedero, provoca enfermedades gastrointestinales recurrentes sobre todo por E. coli.

que de manera progresiva se infiltraron o se vertieron directamente en los cuerpos de agua, afectando el entorno natural, base productiva de actividades agrícolas, ganaderas y pesqueras (Ávila, 1999). Sin embargo, a más de un siglo de la conformación geográfica de la ciénega y el deterioro ecológico del lago de Chapala, la población ha generado estrategias de adaptación en sus prácticas socioculturales, productivas y de consumo, las cuales tienen implicaciones ecológicas, sociales y económicas. Ejemplo de estas estrategias son los mecanismos diversos de acceso al agua para consumo humano, pesca y riego.

\section{Disyuntivas de los grupos locales en el acceso al agua}

\subsection{Usuarios de agua en la ciénega de Chapala michoacana}

En la ciénega de Chapala, el agua para actividades agrícolas y uso doméstico suma el mayor consumo, mientras que las actividades pesqueras se han reducido a las pocas poblaciones ribereñas, y la acuacultura de granja se desarrolla en algunos sitios de Sahuayo y Venustiano Carranza.

Los usos del agua se relacionan con una forma de organización social de los grupos. Para el caso del uso público-urbano hay dos tipos de organizaciones: una de tipo comunitario y otra dependiente de la red municipal en los centros urbanos. La primera corresponde a los Comités de Agua Potable Comunitarios y la segunda a los Organismos Operadores de Agua Potable y Alcantarillado. ${ }^{6}$ Para el caso del uso agrícola del agua,

\footnotetext{
${ }^{6}$ En el ámbito gubernamental están los organismos descentralizados federales, encargados del sector hídrico (Semarnat y Conagua) y pesquero (Comisión Nacional de Acuacultura y Pesca). Sus funciones son normativas en cuanto a la vigilancia en la aplicación de las leyes y reglamentos, y di-
} 
se identifican también dos tipos: unas son las organizaciones civiles que conforman el Distrito de Riego 024 Ciénega de Chapala, y las otras son las organizaciones de pequeño riego, las cuales agrupan a productores agrícolas abastecidos de pozos artesianos. Por su parte, los grupos de pescadores organizados en cooperativas, son los más dinámicos económicamente, pero también existen otros grupos de pescadores no organizados de manera formal, sino en pequeños conjuntos de vecinos y familias.

Las agrupaciones de origen comunitario, sean de agricultores, pescadores y comités de agua potable, en su mayoría son organizaciones sin figura legal. Estas agrupaciones las constituyen integrantes de las comunidades y funcionan mediante usos y costumbres, como los comités de agua potable y las organizaciones de pequeño riego. En estas organizaciones los miembros de las directivas son elegidos por asamblea y su reglamentación se establece de manera autónoma a las autoridades municipales, diseñando sus propias reglas de manera informal, de acuerdo con la experiencia previa de sus miembros y por ensayo y error, según sus vivencias como colectivo en la actividad. Asimismo determinan tarifas y administran sus recursos financieros y establecen mecanismos de distribución del agua, siendo de exclusiva injerencia de la comunidad o del grupo de interés, para el caso del pequeño riego y cooperativas de pescadores. En el cuadro 1 se presentan los principales grupos locales en el manejo del agua en la ciénega de Chapala.

\subsection{Grupos de regantes y los dilemas para acceder al agua}

La vocación productiva de la ciénega de Chapala es básicamente agrícola. Como resultado de la desecación a principios del siglo xx, allí surgió un área aprovechable agrícola con disposición de riego a través de una red de canales y caminos que constituyen el Distrito de Riego 024 Ciénega de Chapala, el cual comprende una región de nueve municipios michoacanos: Villamar, Jiquilpan, Sahuayo, Venustiano Carranza, Briseñas, Pajacuarán, Vista Hermosa, Ixtlán y Tingüindín.

En esta región hidroagrícola, $75.17 \%$ de los 2,360 títulos de concesión de aguas nacionales tiene como destino el uso agrícola, y $16.57 \%$ son aguas para público urbano, según datos publicados en el Registro Público del Agua (Repda) ${ }^{7}$ de la Comisión Nacional del Agua.

El mayor número de concesiones de agua superficial y subterránea está destinado a las actividades agrícolas, como se observa en los cuadros 2 y 3.

rectiva en relación con la aplicación de las políticas y programas nacionales. Estas dependencias regionales y estatales se vinculan con las organizaciones formales en el ramo.

7 El Repda es la estadística oficial por parte de la Conagua para el registro de los títulos de concesión asignados para los diferentes usos. 


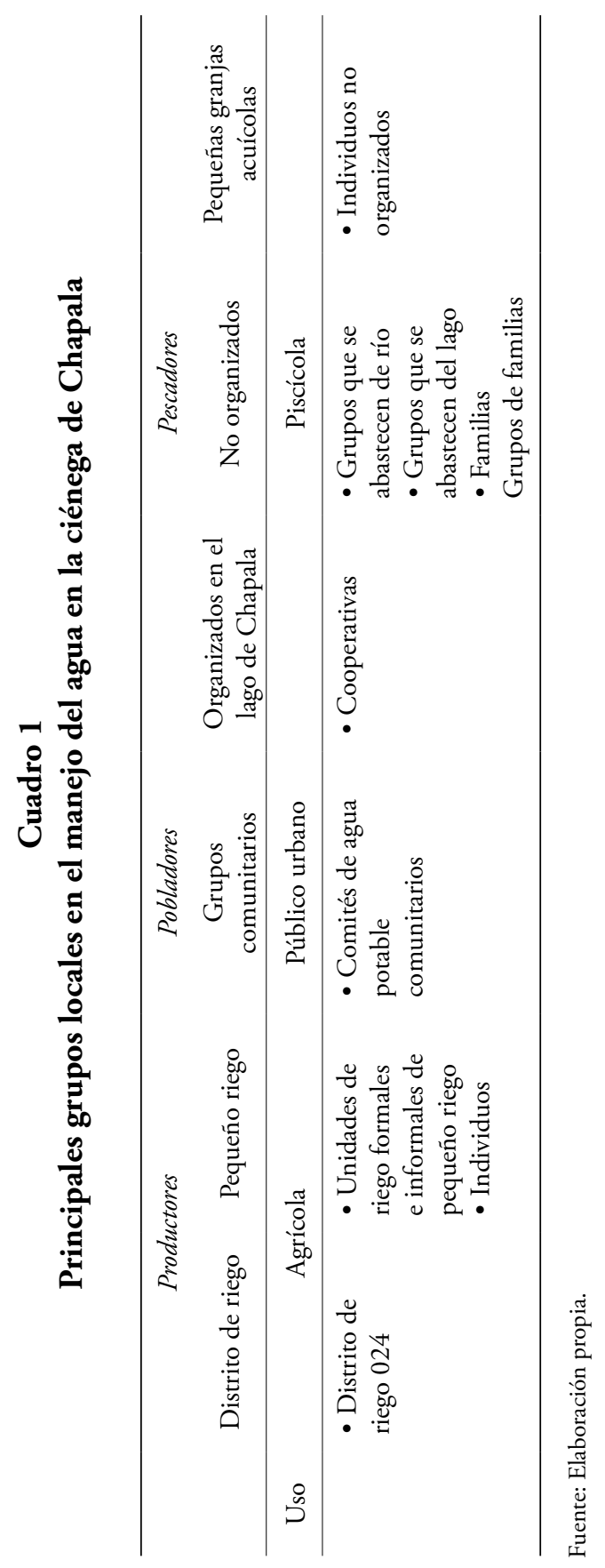




\section{Cuadro 2}

Títulos de concesión de aguas nacionales inscritos en el Repda, marzo de 2008

\begin{tabular}{lcc}
\hline \multicolumn{1}{c}{ Usos } & Número de concesiones & $\%$ \\
\hline Doméstico & 17 & 0.72 \\
Acuacultura & 5 & 021 \\
Industrial & 18 & 0.76 \\
Agricultura & 1774 & 75.17 \\
Múltiples & 45 & 1.91 \\
Servicios & 34 & 1.44 \\
Público urbano & 391 & 16.57 \\
Pecuario & 71 & 3.01 \\
Generador de energía & 2 & 0.08 \\
Otros & 3 & 0.13 \\
Total & 2,360 & 100 \\
\hline
\end{tabular}

Fuente: Elaboración propia con datos del Repda, consultado en marzo de 2008.

\section{Cuadro 3}

Concesiones de aguas nacionales para uso agrícola por municipio en la ciénega de Chapala

\begin{tabular}{lc}
\hline \multicolumn{1}{c}{ Municipio } & Porcentaje \\
\hline Pajacuarán & 96.17 \\
Vista Hermosa & 89.85 \\
Sahuayo & 81.51 \\
Briseñas & 74.64 \\
Venustiano Carranza & 72.20 \\
Villamar & 72.09 \\
Tingüindín & 62.86 \\
Jiquilpan & 56.10 \\
Ixtlán & 37.50 \\
Total & 100
\end{tabular}

Fuente: Elaboración propia con datos del Repda, consultado en marzo de 2008. 
El Distrito de Riego 024 agrupa a 14,925 usuarios ejidatarios y pequeños propietarios. Las autorizaciones de disponibilidad de agua para el Distrito las hace la Comisión Nacional del Agua y el Organismo de Cuenca mediante el Plan de Riegos, estableciendo oficialmente una superficie regable de 15,851 ha (Semarnat, 2006).

Los principales cultivos en la región son maíz, trigo, sorgo, cártamo, hortalizas y garbanzo con la mayor superficie sembrada, y en menor proporción otros como alfalfa, frijol, cebolla, forrajes, jitomate, caña, fresa, frutales y pradera. El maíz del ciclo primavera/verano es el cultivo más importante en cuanto a la superficie establecida, con poco más de 5,000 ha en promedio al año, seguido del trigo, cártamo y sorgo. Por ello se puede afirmar que la región es básicamente productora de granos, ya que en los últimos 10 ciclos agrícolas, en el Distrito se destinó poco más de $74 \%$ de la superficie regada a la producción de estos cuatro cultivos. Mientras que la producción hortofrutícola representa $12 \%$ del total (Conagua, 2005). Por otro lado, la actividad hortícola se ubica sobre todo en las áreas contiguas al lago, en los municipios de Cojumatlán y Venustiano Carranza. ${ }^{8}$

Es importante destacar que durante el año 2007 la región de la ciénega fue la más productiva del país en maíz, obteniendo un rendimiento de hasta 17 toneladas por hectárea encontrándose las mejores cosechas en las áreas de riego de los márgenes del río Duero, entre los municipios de Ixtlán, Vista Hermosa, Pajacuarán y una parte de Venustiano Carranza. En la cosecha 2009 el cultivo de maíz por riego rindió nueve toneladas por hectárea promedio, mientras que el sorgo cinco toneladas por hectárea. En este mismo año, para maíz y sorgo, los gastos estimados por productor fueron: en primer lugar los agroquímicos con 49\%, seguido por las actividades de mantenimiento con 30\% y $21 \%$ los costos de mano de obra contratada.

Estas condiciones de productividad dependen, por un lado, de las condiciones hidroclimatológicas de la región y, por otro, del empleo de agroquímicos. Con respecto a la primera causa, el clima predominante corresponde al subtipo semicálido subhúmedo con lluvias en verano. La época de lluvias comprende de junio a octubre, siendo julio el mes más lluvioso, con lámina de $235 \mathrm{~mm}$. La precipitación media anual es de unos $719 \mathrm{~mm}$ y lluvia invernal menor a 5\% del total anual (Conagua, 2002). Pero también estas condiciones les han resultado contradictorias a los agricultores, ya que se manifiestan lluvias torrenciales que provocan problemas de inundación año con año, tanto en zonas de riego como urbanas,

\footnotetext{
${ }^{8}$ Los cultivos con mayor demanda de agua son: alfalfa, pradera, cańa, frutales, frijol, cebolla, hortalizas, maíz y trigo. Los ciclos de riego con mayor consumo de agua son, por orden en el volumen de consumo: perenne, le sigue el ciclo otońo-invierno y luego el primavera-verano.
} 
situación que les obliga a drenar del lago de Chapala los excesos de agua de las avenidas de los ríos Jaripo, Jiquilpan, Sahuayo y Duero, por medio de las plantas de bombeo del Distrito.

El periodo con escasa precipitación pluvial se da entre febrero y mayo, donde las necesidades de agua son imperantes para los productores agrícolas. Es en este periodo de estiaje que se manifiestan inconformidades entre grupos de usuarios del Distrito, ya que los regantes aguas arriba, los más cercanos a las tomas de derivación del río Duero, las presas Guaracha, Jaripo y Tarecuato, además del lago de Chapala, tienen acceso seguro al agua, no así los usuarios aguas abajo; situación de continuas disputas y quejas ante los módulos de riego.

Estas condiciones de inundación y escasez de agua generan una dinámica de tensión para los productores, de lucha por el agua en los periodos de estiaje y riesgos de inundación y pérdida de cultivos en las zonas más bajas. Así, un clima de insatisfacción con las administraciones de riego del Distrito desincentiva la cooperación colectiva y, en consecuencia, la falta de acuerdos consensuados para resolver problemas comunes.

Es importante señalar que en esta región agrícola -con un siglo de haberse establecido como hasta ahora, y peculiarmente entre los regantes agrícolas, con una estructura oficial en la distribución del agua mediante tres módulos de riego agrupados en el Distrito de Riego 024- no se han podido diseñar y establecer mecanismos tendentes al manejo sustentable de los recursos de uso común, como es el agua para riego. Una explicación es el control gubernamental del agua, ya que hasta 1994 se les transfiere a los usuarios la infraestructura de las obras de la red mayor y menor, quedando a cargo de la Comisión Nacional del Agua las obras de cabeza ${ }^{9}$ y la supervisión general (Conagua, 2005: 24-26). Esta transferencia no significó el control y manejo eficiente del sistema de riego por los usuarios sin experiencia técnica y administrativa, sino una acumulación de problemas no resueltos y, en varios casos, la dependencia de personal técnico. Otra explicación es la dinámica generacional y migratoria, donde los hijos e hijas de los primeros usuarios ejidatarios, en su mayoría no han mostrado interés para continuar cultivando la tierra, sino que emigrar y buscar otras fuentes de ingreso les es más atractivo, como se explica más adelante.

Con respecto a la segunda causa. Los productores de la región refieren que desde hace poco más de 20 años no se empleaban agroquímicos en las zonas de temporal, mientras que en las de riego se han usado desde mediados del siglo pasado. Ahora el uso de éstos ha ido en aumento, sin

\footnotetext{
${ }^{9}$ Se entiende por obras de cabeza a las grandes presas de almacenamiento, las presas derivadoras $\mathrm{y}$ en algunos casos los canales principales de riego.
} 
asesoría técnica la mayoría de las veces, como lo testifica un agricultor del Distrito de Riego: "Ya ahorita como se usaba antes [el fertilizante], ya no da nada. Hay que echarle más para que dé más. Ahora le echan exagerado" (G. Víctor, entrevista personal, 22 de enero de 2010).

La FAO (1997) señala que la relación entre la creciente aplicación de fertilizantes, la pérdida de productividad y la erosión del suelo es muy directa en muchos países, ${ }^{10}$ y esta relación también se observa en la ciénega de Chapala (Sotelo et al., 2005: 49-51). Allí, los fertilizantes nitrogenados más usados son el sulfato de amonio (fabricado con base en amoniaco y ácido sulfúrico), nitrato de amonio (producido con amoniaco y ácido nítrico), urea (amoníaco y dióxido de carbono); además del empleo de plaguicidas. Los criterios ecológicos sobre la calidad del agua en México señalan para el riego agrícola hasta seis miligramos de nitratos y seis de nitrógeno amoniacal (Sedue, 1989), aunque no se tienen referencias de estudios específicos al respecto del agua de riego en la ciénega. El uso de estos agroquímicos -al mezclarse con el agua, son un disolvente y un mecanismo de transporte continuamente en movimiento- explica una parte de la contaminación del agua del lago de Chapala y supone la contaminación de tierras y ríos por los que son arrastrados los residuos tóxicos de los campos de cultivo. ${ }^{11}$

Para los usuarios que se han visto afectados por la limitada disposición de agua para riego y las necesidades de contar con ella para asegurar sus cosechas, han recurrido a una serie de estrategias, caracterizadas por su

${ }^{10} \mathrm{La}$ referencia siguiente puede ser ilustrativa: los municipios afectados por el proceso de declinación de la fertilidad en suelos son: Sahuayo, Cojumatlán de Régules, Venustiano Carranza, Villamar, Jiquilpan, Tizapán el Alto y Tuxcueca. Estas zonas de degradación de suelos coinciden con municipios muy dependientes de la actividad primaria, al sur de la subcuenca. El proceso sucede en zonas de agricultura de riego, pastizal inducido y agricultura de temporal. En los terrenos agrícolas, se recomienda mejorar las prácticas de agricultura, incorporando técnicas de manejo de suelos, para mejorar la calidad de este recurso y aminorar el consumo de agroquímicos (Sotelo et al., 2005: 51).

Para contrastar, en el estado brasileño de Paraná la erosión ha dado lugar a grandes pérdidas de suelo superficial, grandes cárcavas y entarquinamiento de acequias y ríos. En consecuencia, el uso de fertilizantes aumentó 575\% durante el periodo 1970-1986, sin ningún aumento en los rendimientos de los cultivos (FAO, 1997).

${ }^{11}$ Lamentablemente no se conocen referencias oficiales o estudios de centros de investigación donde se reporten datos consistentes de contaminación microbiológica y química en tierras y aguas de la ciénega de Chapala michoacana (con excepción del estudio de Silva et al., 2006). No obstante, la Organización Mundial de la Salud, en las guías para la calidad de agua potable, señala que la presencia de nitratos y nitritos en el agua se ha asociado con la metahemoglobinemia, sobre todo en lactantes alimentados con biberón. La presencia de nitratos se puede deber a la aplicación excesiva de fertilizantes o a la filtración de aguas residuales u otros residuos orgánicos a las aguas superficiales y subterráneas. La concentración de nitrato en aguas subterráneas y superficiales suele ser baja, pero puede llegar a ser alta por filtración o escorrentía de tierras agrícolas o debido a la contaminación por residuos humanos o animales, como consecuencia de la oxidación del amoniaco y fuentes similares. Las condiciones anaerobias pueden favorecer la formación y persistencia del nitrito. La cloraminación podría ocasionar la formación de nitrito en el sistema de distribución si no se controla debidamente la formación de cloramina. La formación de nitrito es consecuencia de la actividad microbiana y puede ser intermitente (oMs, 2006: 15, 330). 
racionalidad individual, según su posición con respecto a las fuentes de acceso al agua, sus posibilidades económicas y de capital social. Las estrategias que se distinguen son: resistir cultivando la tierra, rentarla o venderla.

Las opciones más elegidas por los productores del Distrito de Riego, que soportan la escasez de agua superficial, dados los problemas de distribución, son en primer lugar la resistencia para persistir cultivando sus tierras, particularmente entre quienes tienen la actividad agrícola como su principal fuente de ingresos, a pesar del incremento en el gasto por compra de insumos como semilla y agroquímicos. Estos productores son los primeros que recibieron dotación de tierras ejidales, hoy en su mayoría adultos mayores. Pero también hay una tendencia en la región a abandonar las actividades agrícolas, por ejemplo, en el municipio de Jiquilpan de Juárez con grado de marginación bajo (INEGI, 2005), descendió el porcentaje de personas dedicadas a las actividades primarias, pasó de $28 \%$ en 1990 a $18 \%$ en 2004, y destaca el incremento en las actividades terciarias y en menor medida las secundarias (INEGI, 2000, 2004). Esta tendencia es semejante a la seguida en otros municipios de la región.

Llama la atención que la ciénega se caracteriza por sus altos grados de migración, ya que dos municipios (Villamar e Ixtlán) califican con grado de intensidad migratoria muy alto, cuatro con grado alto (Venustiano Carranza, Jiquilpan, Briseñas y Tingüindín) y dos con grado medio (Vista Hermosa y Sahuayo) (Conapo, 2000). Una de las quejas recurrentes entre los ejidatarios es que a las generaciones jóvenes, sus hijos, ya no les interesa trabajar la tierra, siguen la tendencia de emigrar a Estados Unidos, estudiar o trabajar en las ciudades y quedarse a radicar allí. ${ }^{12}$ Esta dinámica migratoria de los jóvenes ha traído cambios en cómo se relacionan con la tierra las familias residentes en la ciénega, mientras que antes los ejidatarios la trabajaban directamente, ahora son cada vez menos, y quienes lo hacen, son los adultos mayores. Según los testimonios recuperados en trabajo de campo, algunos usuarios han tomado la decisión de rentar una parte o la totalidad, situación común cuando la posesión es de la viuda. Así, la segunda estrategia es rentar la tierra con sus derechos de acceso al agua, cuando ya no hay interés para cultivarla por ninguno de los familiares directos del ejidatario o la ejidataria.

Por último, optan por cambiar de actividad al vender la tierra, cuando ya no se tiene ningún incentivo para sembrarla ni por conservar los derechos de propiedad. La tierra es vendida a otros productores o fraccio-

\footnotetext{
12 Un documento del PNUD (2008) señala que la mayoría de los migrantes michoacanos (68\%) tienen entre 16 y 35 años de edad, es decir, se encuentran en plena etapa productiva, y son originarios del campo, donde carecen de empleo y de recursos para la producción agrícola.
} 
nadores para la construcción de viviendas, como sucede en el polo urbano-económico Jiquilpan-Sahuayo.

Con respecto a los usuarios de pequeño riego, éstos son pequeños productores, algunos también son usuarios del Distrito de Riego. Algunos tienen la concesión en forma individual y otros están agrupados en asociaciones civiles, ligados por proximidad mediante una perforación. Este tipo de agrupaciones se constituye a través de las relaciones de confianza, familiares y vecinales, con el fin de alcanzar una meta común o cubrir una necesidad, como el abasto de agua para riego. Así, el mayor número de organizaciones de regantes de pozo artesiano, en función, se localizan en las zonas de menor acceso a agua del sistema de riego. Estas organizaciones administran las tandas de agua y sus respectivas cuotas por medio de una directiva y no participan en las gestiones o planes de riegos con el Distrito, sino que son de manejo autónomo. Internamente ejercen cierto control de sus recursos (agua y dinero) entre sus miembros, traspasados por vaivenes de fricciones, arreglos informales y consensos, pero no se ha detectado la cohesión de intereses en acciones de beneficio mutuo entre organizaciones de regantes en la región.

En los grupos no formalizados se pueden distinguir dos tipos: los que gozan de derechos de concesión, es decir, tienen permiso oficial para el aprovechamiento del agua subterránea, y quienes operan en forma irregular o clandestina.

En general, los usuarios con derecho al agua superficial del Distrito son quienes están registrados en el Padrón de Usuarios de un módulo de riego. ${ }^{13}$ No tienen preferencia en la aplicación de riegos quienes aprovechan alguna perforación. Sin embargo, varios de estos usuarios, los ubicados en las zonas más alejadas de las tomas de derivación, son afectados porque no les llega el agua o no es suficiente. Éstos han tomado la alternativa de regar con agua subterránea, a pesar de la mala calidad detectada en varias zonas ${ }^{14} \mathrm{y}$ al gasto en energía eléctrica, o regar directamente de los ríos y

${ }^{13}$ El Distrito de Riego 024 Ciénega de Chapala agrupa tres módulos de riego: La Palma, Cumuato y Ballesteros de San Cristóbal. Cada uno de estos módulos tiene un padrón de usuarios a quienes se les administra el acceso al agua de riego.

${ }^{14}$ Según un estudio, hecho en 2003 y publicado en 2006, sobre la calidad química del agua subterránea y su relación con el aumento de la salinización del suelo en la ciénega de Chapala, se definió el grado de peligrosidad de esta agua para los suelos en términos de sodicidad y salinidad. Así, los resultados indicaron que "los pozos perforados sobre roca volcánica registran valores menores de $1.0 \mathrm{dS}{ }^{\mathrm{m}-1}$, por el contrario, en aquellos pozos que extraen agua de horizontes lacustres, las conductividades llegan a ser de $4.5 \mathrm{~d} \mathrm{~S}^{\mathrm{m}-1}$, por lo que representan un alto riesgo para la agricultura regional [los pozos] con profundidades menores de $70 \mathrm{~m}$, en su mayoría extraen agua de mala calidad química [...] En general, prevalecen los suelos con intervalos de salinidad de ligera a moderadamente salinos y representan $55 \%$ del total del área de estudio y cuyos riegos se dan con aguas tipo 2 [...] que puede utilizarse en actividades agrícolas con ciertas restricciones, especialmente en selección del tipo de cultivos, los cuales deberán ser tolerantes a estos intervalos de salinidad y sodicidad”. Le sigue el agua "tipo 3, es un agua no recomendable para su uso en actividades agrícolas [...] el riesgo de 
canales donde son vertidas aguas residuales sin tratamiento. ${ }^{15}$ También es común que apliquen riegos del dren, con el riesgo de disminución de su productividad, al ser agua saturada con residuos de agroquímicos por los escurrimientos de tierras arriba, elección racional de los agricultores ante la posibilidad real de perder sus cultivos.

Los sistemas de las aguas subterráneas son especialmente vulnerables a la contaminación, ya que a menudo son difíciles y costosos de corregir. Es posible que algunos contaminantes estén presentes en altas concentraciones, a pesar de que el agua puede parecer limpia y segura. El uso de agroquímicos en relación con el drenado de agua en tierras de cultivo provoca el arrastre de residuos, mismos que viajan por los drenes aguas abajo en dirección al lago de Chapala, pero en el intermedio, es común el uso de agua para riego y abrevadero de ganado. Aunque la saturación de componentes químicos provoque baja productividad del cultivo y contribuya al deterioro de la calidad de la tierra, para los productores es la opción inmediata cuando tienen el acceso al agua de canales como única fuente en temporada de estiaje.

Otros usuarios de pequeño riego con acceso a agua subterránea, los que no pueden conseguir agua de las derivaciones mediante arreglos informales con los responsables del módulo, emplean el agua disponible o siembran únicamente durante la temporada de lluvias.

Cabe mencionar que quienes utilizan aguas subterráneas para uso agrícola, en pozos con profundidades menores de 70 metros, en su mayoría extraen agua de mala calidad química (aunque no se descartan problemas de deficiente calidad microbiológica, no existen datos que lo demuestren), ya que la porción central de la ciénega se caracteriza por una alta concentración de pozos y altos regímenes de extracción de agua subterránea. Los valores mayores de salinidad en los suelos se presentan en el sureste y en la zona noroeste. Las áreas de mayor salinización de suelos corresponden a los lugares aledaños al área geotérmica de Los Negritos (sureste de la Ciénega), así como la zona noroeste (ejido La Magdalena, municipio Venustiano Carranza), provocando significativas mermas económicas a los agricultores por la disminución de los índices de productividad; como es el caso del trigo, cuyo rendimiento por hectárea se reportó sólo en la década 1992-2002, cuya disminución fue de hasta $60 \%$

degradación de los suelos por procesos de salinización y sodificación es acelerado" (Silva et al. 2006: 503-513). Mientras que la del tipo 1 es agua que no afecta a los suelos y no representa restricciones para el desarrollo de los cultivos.

${ }^{15}$ Por lo que no se descarta la contaminación de los productos agrícolas, al regar los cultivos con aguas residuales no tratadas. Es el caso de los productores ubicados en la zona de riego de Jiquilpan y Sahuayo. Los criterios ecológicos de la calidad del agua para uso agrícola señalan como límite 1,000 miligramos por litro de coliformes fecales, mismo parámetro para las fuentes de abastecimiento de agua potable (Sedue, 1989). 
(Silva et al., 2006). En estas zonas los campesinos con tierras de riego prefieren las aguas superficiales y califican de mala calidad a las subterráneas por las afectaciones a la productividad de sus cultivos.

En la ciénega, otro problema en el sector agrícola con respecto al agua es la baja eficiencia de los sistemas de riego y la falta de sistemas tecnificados (2.1\%, según la Conagua, 2005), por lo que sufren pérdidas de agua por infiltración y evaporación al conducirla por canales de tierra abiertos y por una escasa infraestructura de control de gasto y medición en los puntos de control, lo que señala diferencias entre los volúmenes de agua autorizados y los volúmenes utilizados por los usuarios, situación causal de problemas de distribución del agua entre ellos, ubicados aguas arriba y aguas abajo en el Distrito.

En particular el lago de Chapala es una de las fuentes de riego y de agua potable para la ciudad de Guadalajara, presenta una extracción desmedida, una alta contaminación por plaguicidas, desechos industriales y descargas urbanas que generan niveles importantes de fósforo inorgánico, cromo, cianuro, plomo y mercurio (Sotelo et al., 2005: 46-49). Además posee elevados rangos de evaporación, azolve y retención de escurrimientos, así como una sobrepoblación de lirio y tule, que además de acelerar la evaporación, alteran el fitoplancton y con ello la cadena alimentaria de los peces; este tipo de flora acuática también concentra contaminantes y alberga una gran diversidad de insectos que representan riesgos para la salud (Valdez et al., 2000).

En suma, la disposición de agua para los productores no es homogénea ni equitativa. Los regantes han tenido que recurrir a una serie de estrategias para obtener agua, en primer lugar, de las fuentes superficiales, y en segundo de las subterráneas. Los derechos de acceso al agua los adquieren al asociarse como usuarios, sea del Distrito de Riego o de los pozos artesianos. Pero para otros, los bajos rendimientos económicos del campo y las posibilidades de emigrar, los ha estimulado a rentar o vender la tierra junto con todos los derechos de agua.

\subsection{Problemas de acceso y contaminación de agua para consumo bumano}

La densidad de población en la cuenca Lerma-Chapala es de 190 personas por $\mathrm{km}^{2}$, casi cuatro veces más del promedio nacional. En el área hidroagrícola de la ciénega de Chapala hay una población total de 201,026 habitantes en 303 comunidades de los nueve municipios que la comprenden, de las cuales aproximadamente $77 \%$ del servicio de agua potable es atendido por organizaciones comunitarias o mediante los llamados co- 


\section{Esquema II}

\section{Cuerpos de agua y vegetación acuática en la ciénega de Chapala}

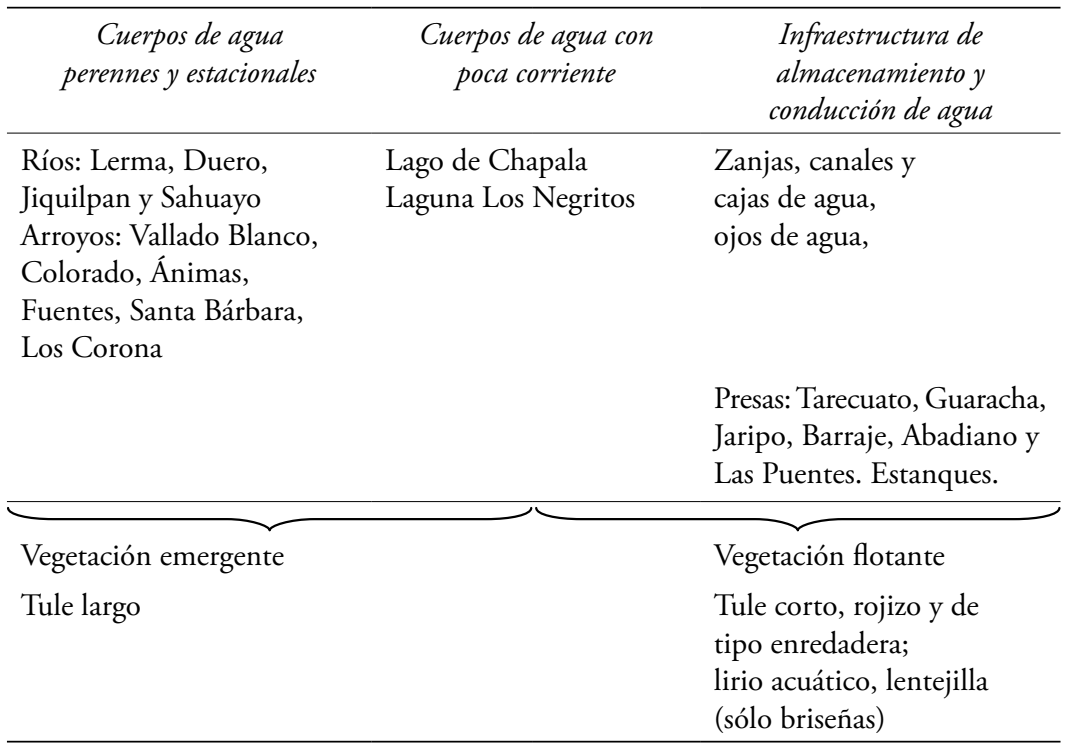

Fuente: Elaboración propia.

mité de agua potable. ${ }^{16}$ Pero todas las cabeceras municipales son administradas en la distribución del agua por los organismos operadores de agua potable, instancias descentralizadas del municipio.

El agua para consumo humano se extrae de pozos profundos correspondientes al área del acuífero denominado Ciénega de Chapala, en el que fuentes oficiales (Semarnat, 2006; Conagua, 2002) señalan un desequilibrio entre la recarga y la extracción de agua en el acuífero, al tener una recarga media anual de $14.4 \mathrm{~mm}^{3}$, frente a $72 \mathrm{~mm}^{3}$ anuales concesionados, lo que resulta en un déficit de disponibilidad media anual de $-58 \mathrm{~mm}^{3}$. La cifra indica que "no existe volumen disponible para nuevas concesiones en la unidad hidrogeológica denominada acuífero Ciénega de Chapala" (Conagua, 2002).

Junto con la baja disponibilidad de agua subterránea para todos los usos, el crecimiento poblacional desordenado ha favorecido la contaminación de las aguas superficiales, al verter aguas negras urbanas e industriales sin tratamiento en los lechos de los ríos. Esta situación es muy clara con las acciones emprendidas a partir de la década de los años cuarenta con el corredor industrial Lerma-Toluca-Ixtlahuaca-Atlacomulco, las cuales tomaron al río Lerma como abastecedor urbano e industrial de agua pero, desafortunadamente, también se apropiaron de su cauce para

${ }^{16}$ Según la información obtenida en trabajo de campo de enero a junio de 2009. 


\section{Esquema III \\ Fuentes de contaminación directa al lago de Chapala}

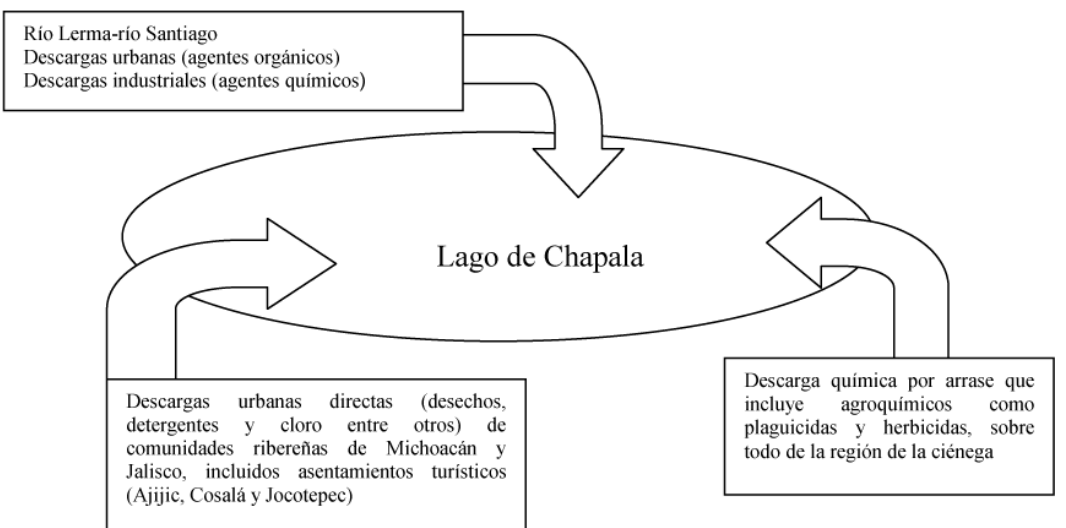

Fuente: Elaboración propia.

liberar desechos provenientes de las ciudades en formación y de las empresas en pujante consolidación.

En las zonas agrícolas de la ciénega de Chapala, el uso de agroquímicos es alto, lo que ha generado efectos adversos en la calidad de los recursos hídricos, afectando la vida acuática, la fauna e incluso con riesgos para la salud humana. Los residuos agroquímicos empleados en las actividades agrícolas de los distritos en la Ciénega y en Jamay, que por arrastre llegan al lago de Chapala, son altos en fosfatos (esquema III).

Las principales vías de exposición humana a los metales pesados identificados en Chapala son: agua para consumo humano, recreación y consumo de peces. En el caso de las especies acuáticas, los metales son incorporados tanto por el agua como por los sedimentos, que se acumulan en el tejido que después consumen los seres humanos, y es sobre todo esta vía de exposición la más significativa (Ayla y Ford, 2001). Además, en los sedimentos del lago se ha encontrado arsénico, cromo, cobre, manganeso, plomo y níquel. ${ }^{17}$ En 1993, Hansen y Van Afferden monitorearon la concentración de metales en los sedimentos del lago de Chapala y reportan lo que se presenta en el cuadro 4.

La mayor presencia de compuestos orgánicos a lo largo del río Lerma son los derivados del proceso del petróleo: tolueno, gasolina, fenoles y polibencenos se encontraron en Salamanca, y en esta misma área y La

\footnotetext{
${ }^{17}$ La intoxicación por consumo de aguas contaminadas con arsénico provoca alteraciones cardiacas, vasculares y neurológicas, lesiones hepáticas y renales, afectaciones en el aparato respiratorio y lesiones cutáneas que avanzan progresivamente hasta la neoplasia (Frers, 2005).
} 


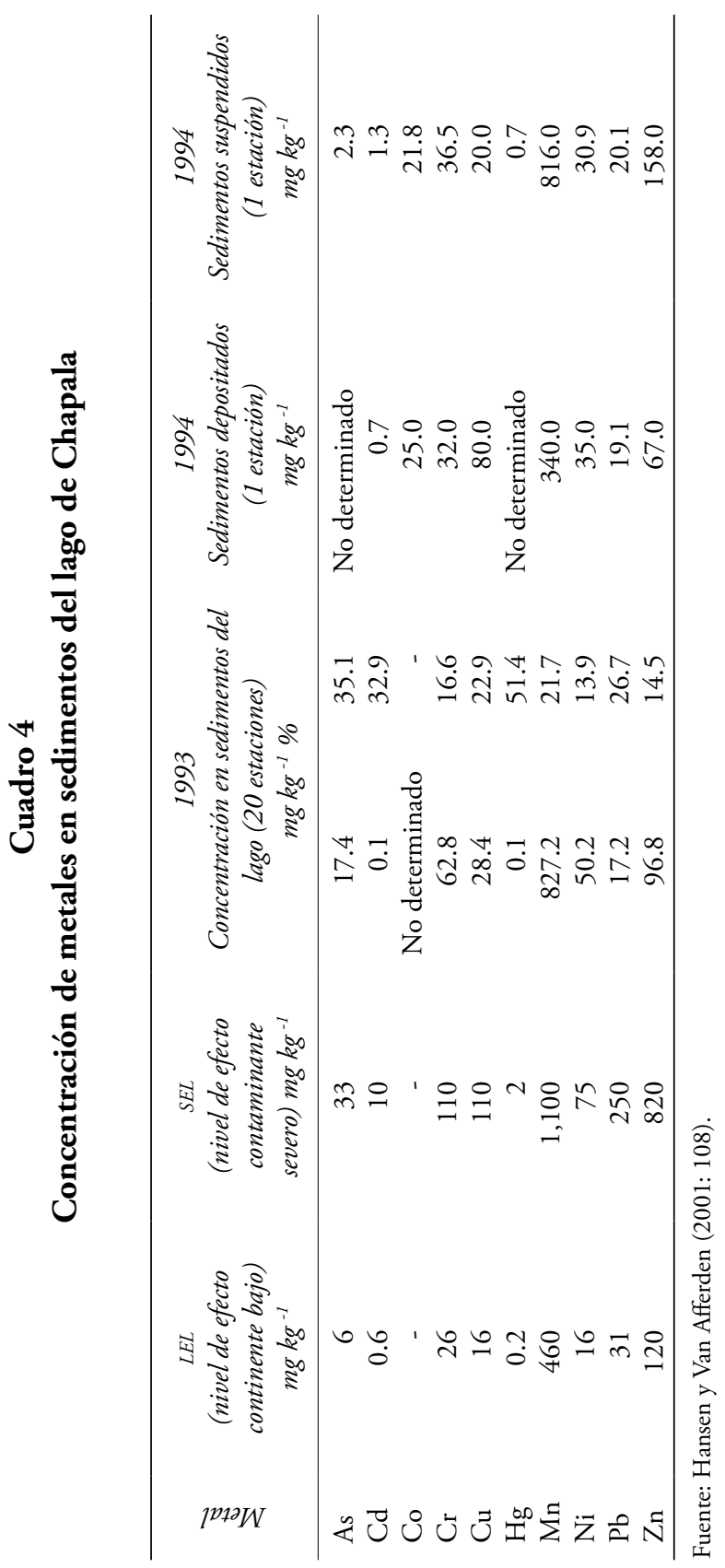


Piedad los niveles más altos de plaguicidas (Hansen y Van Afferden, 2001).$^{18}$ En un estudio realizado en el río Lerma y sus afluentes se señala:

Con respecto a las descargas monitoreadas en la cuenca, el 70\% de las mismas presentan altos niveles de toxicidad y $13 \%$ son medianamente tóxicas. En lo que respecta a la demanda bioquímica de oxígeno, el $83 \%$ de las descargas no cumplen con los límites permisibles de descarga para riego agrícola, mientras que para la protección de la vida acuática (criterio más estricto) únicamente el 4\% de las descargas lo cumplen. Para coliformes fecales, el 36\% de las descargas no cumplen con los límites máximos permisibles (1000 NMP/100 mL). En cuanto a nutrientes, el $54 \%$ de las descargas monitoreadas presentan concentraciones de nitrógeno superiores a las permisibles, y 19\% de las descargas sobrepasan los límites permisibles de fósforo total. Para sólidos suspendidos totales, únicamente el 15\% de las descargas cumple con la NOM-001-ECOL-1996 para los tres criterios de descarga. Bajo esta misma premisa, únicamente el $34 \%$ de las descargas cumple con las restricciones con respecto al contenido de grasas y aceites (Mantilla et al., 2000).

Los municipios de Sahuayo, Jiquilpan y Venustiano Carranza vierten aguas negras y grises poco o nulamente tratadas a los canales de riego, provocando riesgos de contaminación en los cultivos, en la salud de los campesinos, consumidores y animales: al beber el ganado, regar cultivos de consumo humano y animal, y afectar la flora y la fauna acuática, además de provocar azolvamientos y procesos de eutrofización. ${ }^{19}$

Las bacterias patógenas que contaminan el agua causan enfermedades, se encuentran en las excretas de los seres humanos y de los animales de sangre caliente (mascotas, ganado y animales silvestres). Se pueden transmitir por medio del agua, de los alimentos, de persona a persona y de animales a seres humanos. Las bacterias que más afectan la salud pública son Vibrio cholerae, causante del cólera; Escherichia coli, Campylobacter jejuni y Yersinia enterocolitica, causantes de gastroenteritis agudas y diarreicas; Salmonella typhi, que produce fiebres tifoideas y paratifoideas; y Shigella, causante de disentería. Estas bacterias llegan a los cursos de agua mediante las descargas de aguas municipales sin tratar o con tratamiento

${ }^{18}$ Al respecto, Paré (1989) señala que en el río Santiago, otro de los afluentes importantes de aporte hídrico al lago, 25 empresas vierten discriminadamente sus desechos, entre ellas Celanese, Industrias Ocotlán, Cyba-Geygi, Cyanamid, Productos de Cola, Penwalt e Industrias Petroquímicas Mexicanas, todas ubicadas en el corredor industrial La Barca-El Salto; además el río recibe descargas urbanas de Poncitlán y Ocotlán, Jalisco.

${ }^{19}$ Un río, un lago o un embalse sufren eutrofización cuando sus aguas se enriquecen en nutrientes. A primera vista podría parecer que es bueno que las aguas estén repletas de nutrientes, pues sería más adecuado para los seres vivos. Pero la situación no es tan sencilla. El problema está en que si hay exceso de nutrientes crecen en abundancia las plantas y otros organismos. Más tarde, cuando mueren, se pudren y llenan el agua de malos olores y le dan un aspecto nauseabundo, disminuyendo drásticamente su calidad. El proceso de putrefacción consume gran cantidad del oxígeno disuelto y las aguas dejan de ser aptas para la mayor parte de los seres vivos. El resultado final es un ecosistema casi destruido (http://www.tecnun.es/Asignaturas/Ecologia/Hipertexto/11CAgu/150Eutro.htm, 9 de junio de 2009). 
deficiente, del drenaje pluvial, de las descargas provenientes de plantas de procesamiento de carne de ganado y aves, y de escorrentías que pasan por los corrales de ganado (Frers, 2005). En este sentido, es imperativo atender los Criterios de Calidad de Agua para consumo humano (Sedue, 1989), ya que estos factores de contaminación tienen relación con los datos de morbilidad emitidos por la Secretaría de Salud entre los ańos 2000 y 2006 para los municipios de Jiquilpan, Venustiano Carranza y Cojumatlán, donde aparecen entre las cinco principales causas de consulta externa: las infecciones en el tracto gastrointestinal (Sistema Nacional de Salud, Secretaría de Salud, Jurisdicción Sanitaria 02, Zamora, Michoacán).

Además, las aguas poco salubres han estimulado el incremento de compra de agua embotellada, lo que indica los cambios en las conductas de consumo que se están adoptando y generalizando entre la población urbana y rural. En el hogar, se selecciona el agua para los diversos usos, según la información de su procedencia y la percepción de pureza en cuanto a su color y sabor, se determina si se usa directamente para beber y para procesar alimentos o si se trata con algún tipo de desinfección (cloro o hervor) antes de consumirla. Entre la población urbana es común la ingesta de agua embotellada, incluso para el procesamiento de alimentos, debido a la percepción de mala calidad en la toma domiciliaria, lo que fomenta cada vez más la compra de agua en su presentación de 19 litros, incluso en las localidades rurales. Este rubro representa, al menos en Jiquilpan y Sahuayo, casi $10 \%$ del ingreso de una familia promedio de cinco integrantes, con el ingreso económico de un miembro con salario mínimo. ${ }^{20}$

\subsection{Los pescadores y la crisis en la pesca}

Los grupos de pescadores se ubican en las riberas actuales del lago de Chapala y otras localidades con acceso a los lechos de los ríos Duero y Lerma, y en ańos recientes se han establecido criaderos de trucha, tilapia y carpa que se abastecen de agua subterránea.

${ }^{20}$ En promedio, una familia compuesta por cinco personas consume dos garrafones de agua a la semana; esta familia con un ingreso semanal de 364 pesos, de una persona que gana el salario mínimo (51.95 pesos diarios en el año 2009 en el área geográfica "C” que califica al estado de Michoacán), gasta en agua embotellada $8.8 \%$ de su ingreso semanal. Si consume dos garrafones por semana en promedio gasta 32 pesos; en cuatro semanas son 128 pesos, por 12 meses resulta un gasto de 1,536 pesos anuales en agua embotellada, además del gasto de agua en otras presentaciones y en el consumo de refresco. Este gasto se suma al pago de agua al Organismo de Agua Potable, que para el municipio de Jiquilpan en la tarifa 1 es de 118 pesos mensuales (1,416 anuales), mientras que en la tarifa 2 es de 97 y en la tarifa 3 es de 60 pesos mensuales. 
Como se señaló, la actividad agrícola del Bajío y la ciénega tiene un fuerte efecto contaminante por agroquímicos, aguas residuales y desechos industriales, pero hay que agregar la ausencia de ordenamiento pesquero. En específico, en Jalisco y Michoacán preocupa el uso indiscriminado de agroquímicos en agricultura y la sobreexplotación de aguas superficiales y subterráneas. En el caso de los agroquímicos, los plaguicidas organoclorados arrastrados por la lluvia llegan al lago de Chapala porque es en este punto donde se cierra la cuenca (Gómez-Reyna, 2007). Se han detectado 12 sustancias denominadas contaminantes orgánicos permanentes, ocho de ellos son plaguicidas como aldrín, dieldrín, endrín, clordano, DDT, toxafeno, mirex у нсв. El dieldrín y el mirex se asocian con enfermedades tumorales malignas (cáncer). Además de un compuesto industrial llamado bifenilo policlorado y productos generados por procesos de combustión, como la quema agrícola o de basura y la producción de cemento. La mayoría de estas sustancias tiene efectos nocivos en las funciones reproductivas, de desarrollo y respuesta inmune de los organismos, incluido el ser humano (Zárate, 2007; Pimentel et al., 1996).

En el cuadro 5 se presentan los resultados del estudio llevado a cabo entre 1993 y 1994 , donde se identificaron metales pesados en el sedimento del lago de Chapala, destacando la presencia de manganeso, cinc y cromo. En una investigación posterior llevada a cabo por el Centro de Ciencias Exactas e Ingenierías de la Universidad de Guadalajara (2009), Zárate del Valle y colaboradores señalan la detección, además de los metales mencionados, de alta concentración de fósforo, azufre y flúor, asociada con el arrastre de fertilizantes, descargas industriales y municipales.

Ante este conflicto ecológico, la diversidad biológica de peces ha disminuido. Datos oficiales confirman esta tendencia a la baja en la producción pesquera, no sólo en el lago de Chapala, sino en todo el estado de Michoacán. ${ }^{21}$

El lago alguna vez fue abundante en peces nativos, incluidas tres especies de pescado blanco muy apreciado, de sabor delicado (Chirostoma spp). Así, las autoridades federales en coordinación con el estado de Jalisco comenzaron un proyecto para el rescate del pescado blanco de Chapala, que por las condiciones ambientales inestables y la pesca indiscriminada, está en grave peligro de extinción: ${ }^{22}$ en la actualidad no figura como especie de mayor captura.

21 "La producción pesquera en Michoacán descendió de 32,250 toneladas producidas en 1996 a 18,288 en 1999, teniendo una recuperación en los siguientes ańos hasta llegar a 26,509 en 2004, y descendiendo nuevamente a 23,010 toneladas en 2005, la producción en aguas continentales representó el $94.3 \%$ y la de aguas marinas el 5.7\%, lo que nos indica claramente que la pesca en Michoacán es prácticamente de aguas dulces. [...] En el año 2005 la producción representó menos del $0.5 \%$ del PIB, y nos ubicó en el treceavo lugar a nivel nacional, sitio que hemos ocupado desde 2003" (Plan Estatal de Desarrollo, 2008-2012).

${ }^{22}$ En abril de 2008 se estableció un programa regional con Semarnat, cuya finalidad fue apoyar la instalación de granjas acuícolas para criar pescado blanco ( $A B C$, Zamora, 14 mayo de 2008). 
Cuadro 5

Especies de mayor captura en Petatán, Cojumatlán de Régules

\begin{tabular}{lll}
\hline \multicolumn{1}{c}{ Nombre común } & \multicolumn{1}{c}{ Nombre cientifico } & \multicolumn{1}{c}{ Temporalidad } \\
\hline Bagre & Ictalorus dugesi & Febrero-octubre \\
Carpa & Cyprinus carpio & Julio-octubre \\
Tilapia & Oreochromis mozambique & Todo el año \\
Charal & Chirostoma agre, Chirostoma & Todo el año \\
& chapalae y Chirostoma diazii & \\
\hline
\end{tabular}

Fuente: Trabajo de campo, marzo de 2008.

El nivel de contaminación de este cuerpo de agua también ha generado una serie de cambios en las artes de pesca; por ejemplo, la contaminación concentrada sobre todo en las orillas por el efecto del viento obliga a realizar la pesca lago adentro con métodos de captura distintos, dada la profundidad, o bien elaborar algunos métodos sui generis que garanticen la captura de ciertas especies, tal es el caso del charal (foto I, cuadro 6). El testimonio de un pescador de Petatán ejemplifica lo descrito: "Antes echábamos los tumbos un día antes por ahí de las dos o tres de la tarde, los dejábamos toda la noche y recogíamos el pescado muy de mañana; ahora hay que navegarle mucho, desde las seis de la mañana meternos hasta el centro para sacar algo, el pescado busca los lugares más limpios, con menos suciedad y lirios" (J. Víctor, entrevista personal, 8 de abril de 2008).

\section{Foto I}

\section{Canasta charalera en Petatán, Cojumatlán de Régules}

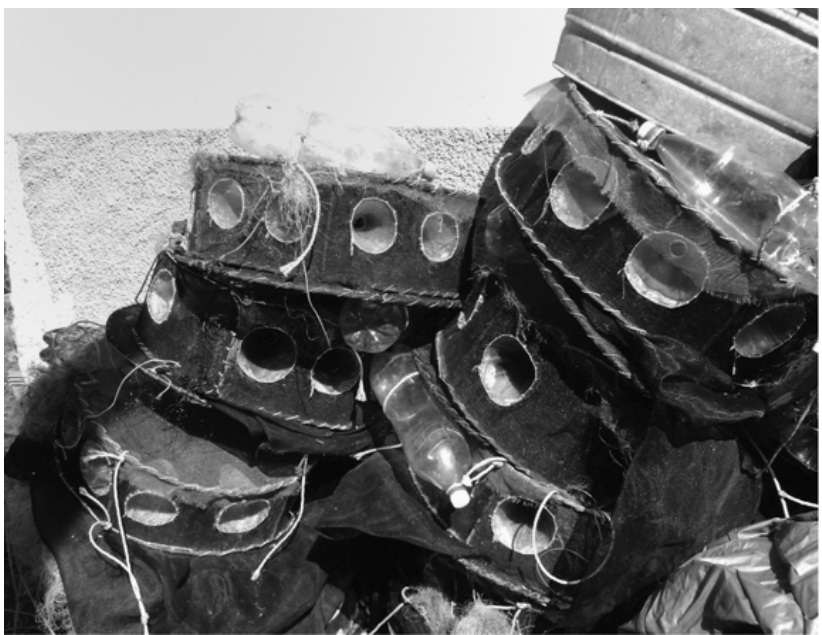

Fuente: María Antonieta Ochoa-Ocańa. 


\section{Cuadro 6 \\ Artes de pesca en Petatán, Cojumatlán de Régules}

\begin{tabular}{ll}
\hline \multicolumn{1}{c}{ Tecnología } & \multicolumn{1}{c}{ Descripción y uso } \\
\hline Tumbo & $\begin{array}{l}\text { Red de malla de nylon } 2.5 \text { a } 3 \text { pulgadas que se extiende en áreas } \\
\text { de poca profundidad (.75 a } 1 \text { metro), se utiliza para pescar tilapia, } \\
\text { pescado blanco, carpa y bagre }\end{array}$ \\
Canasta charalera & $\begin{array}{l}\text { Estructura metálica de } 50 \mathrm{~cm} \text { de diámetro recubierta con malla } \\
\text { plástica de diámetro cerrado, emplea la parte superior de embases } \\
\text { plásticos de } 2 \text { litros a manera embudo y de boya }\end{array}$ \\
Atarralla & $\begin{array}{l}\text { Red de malla de entre } .5 \text { y } 2.5 \text { pulgadas. Se emplea para pescar } \\
\text { charal y pescado blanco }\end{array}$ \\
Puya & $\begin{array}{l}\text { Garrocha de madera en cuyo extremo se ubican tres agujas grue- } \\
\text { sas atadas con hilo cánamo, nylon y reforzado con alambre. Se } \\
\text { utiliza para capturar ranas }\end{array}$ \\
\hline
\end{tabular}

Fuente: Elaboración propia.

La canasta charalera, ingeniosamente construida por los pescadores, es una herramienta local de pesca, empleando material de reciclado (envases de refrescos).

En general, la explotación de los recursos lacustres no requiere de gran tecnología, las actividades de subsistencia están fincadas en el conocimiento del comportamiento biológico de los recursos y de su espacio; este conocimiento permite identificar y seleccionar el lugar y el momento para explotar los recursos (Sugiura et al., 1998); sin embargo, ante un ecosistema alterado se dan estrategias de adaptación según los cambios en el entorno.

En la región se han establecido varias granjas acuícolas, algunas con área de restaurante y venta directa al público. Esta actividad constituye una alternativa ante el desempleo y la baja productividad agrícola y ganadera, además de que los consumidores buscan pescado limpio dadas las condiciones de contaminación de las especies capturadas en el lago de Chapala. Actualmente opera la Asociación de Acuicultores de la Ciénega, que concentra un total de 30 miembros. El bagre y la tilapia son las especias que se crían en mayor cantidad (E. Arceo, entrevista personal, 18 de junio de 2008).

La actividad pesquera emplea a más de 2,500 pescadores registrados en 68 uniones o cooperativas, que utilizan más de 1,000 embarcaciones de madera y de fibra de vidrio, de las cuales $30 \%$ opera con motor y el resto con remo, así como un total de 25,000 artes de pesca ${ }^{23}$ (Guzmán et al., 2001).

${ }^{23}$ La actividad pesquera está en crisis, como se evidencia en el diagnóstico del gobierno del estado de Michoacán: "La actividad acuícola y pesquera en el estado no ha tenido el desarrollo e im- 
A pesar de las dificultades para continuar su labor, se pueden identificar dos tipos de pescadores: los organizados en cooperativas y en la asociación de acuicultores, y los que trabajan en pequeños grupos familiares, de vecinos o en forma individual. Todos ellos han readaptado la actividad a las condiciones cambiantes ambientales y a las poblaciones de especies, así como al mercado. En esta actividad el intermediario ha ocasionado que el control de precios esté en sus manos, el cual alcanza en promedio entre tres y cuatro pesos el kg entre los pescadores, cuando en los mercados de Guadalajara y la ciudad de México, a donde se dirige el producto, el costo oscila entre 20 y 40 pesos.

Esta situación ha sido un fuerte impulso para que los pescadores no sólo realicen actividades de pesca, sino que la combinen con agricultura, ganadería, artesanía, actividades forestales y turismo, con el fin de completar su gasto familiar, además de la emigración, lo que caracteriza a la región como expulsora de población económicamente activa. ${ }^{24}$

\section{Conclusiones}

La disposición de agua en la ciénega de Chapala para las actividades humanas obedece a patrones de uso ligados a las actividades primarias tradicionales, como la pesca y la agricultura. Estas actividades emplean agua subterránea y superficial de los cauces naturales de ríos, arroyos y del lago de Chapala. En esta última, en mayor o menor medida, los estudios han demostrado fuentes contaminantes por descargas urbanas, arrastre de agroquímicos y residuos industriales, que representan riesgos a la salud de las poblaciones humanas, tanto por su exposición directa como por el consumo de hortalizas, carne y pescado, organismos en los que se depositan bacterias, metales pesados y otros tóxicos.

También son los grupos de pescadores y agricultores quienes han sido afectados más sensiblemente por la baja disponibilidad de agua y la contaminación de ésta. Tales afectaciones se reflejan en un estado crítico para mantener sus actividades como fuente principal de ingresos. Para el caso

pulso adecuados, debido entre otras causas a la problemática que se genera en torno a los embalses y la zona costera, y se pueden resumir en: sobreexplotación de especies en los embalses, incumplimiento de normas oficiales como épocas de veda o zonas de captura, falta de planes de manejo acuícolas y pesqueros, explotación pesquera centrada en pocas especies, poca o nula capacitación y acompańamiento técnico en proyectos de desarrollo acuícola y pesquero y falta de modernización de la infraestructura" (Plan Estatal de Desarrollo, 2008-2012).

${ }^{24}$ Los nueve municipios de la región ciénega hidroagrícola califican con grado de intensidad migratoria alto y muy alto, sólo Vista Hermosa y Sahuayo calificaron como medio en el ańo 2000. Mientras que en 2005 casi todos los municipios calificaron con grado medio, salvo Jiquilpan y Sahuayo: con grado bajo (estimaciones del Conapo con base en el XII Censo General de Población y Vivienda, 2000, y cálculos del Conapo con base en el ir Conteo de Población y Vivienda 2005 y la Encuesta Nacional de Ocupación y Empleo 2005, IV Trimestre). 
de los productores agrícolas, se suman los altos costos de producción y la tendencia a la baja productividad, por lo que están llevando a cabo otras alternativas, como rentar o vender la tierra, o incluso migrar de la región.

La conducta de persistencia sociocultural como productores del campo es más evidente en las personas con mayor edad, entre quienes se observa un aferramiento mediante la tradición, el sentimiento afectivo a la propiedad. Pero esta situación cambia radicalmente entre los hijos de los productores actuales, quienes han optado por emigrar de la región a los centros de trabajo urbanos y a Estados Unidos, por lo que son realmente pocos los hijos que continúan con las actividades agrícolas. En este sentido se explica el incremento de tierras agrícolas rentadas con derecho a riego, del acaparamiento de tierras por parte de medianos y grandes productores de granos y hortalizas; además de la venta de tierras al mejor postor, donde el cambio de uso de suelo agrícola por habitacional está presente en las áreas circundantes a los grandes centros urbanos.

En el caso de los pescadores, es evidente la disminución de esta actividad lacustre, producto de la merma en el número de especies, de la cantidad de captura y del tipo de especies comercializadas en el mercado local, afectaciones causadas por la contaminación y los bajos ingresos de los pescadores.

Por otro lado, los comités de agua potable comunitarios desarrollan sus actividades de abasto a la comunidad sin relacionarse con los otros tipos de usuarios. Hasta la fecha en que se realizó este trabajo, no se tiene información fidedigna que demuestre la contaminación de agua de pozos profundos para consumo humano, aunque sí se ha detectado agua subterránea de mala calidad para riego. Sin embargo, el incremento en el consumo de agua embotellada en los centros poblacionales rurales y urbanos habla de la desconfianza en el consumo directo de la red pública.

Las organizaciones locales, formales e informales, en el manejo de agua, muestran relaciones interpersonales fuertes en su interior, sobre todo en los grupos de tamaño pequeño, donde fricciones como los arreglos forman parte de las dinámicas comunes. Es el caso de las organizaciones de regantes de pozo artesiano y los comités de agua potable. Empero, llegar a arreglos y a consensos en el reparto de agua en el Distrito de Riego, entre todas las partes en conflicto, ha sido problemático, por el mayor número de usuarios y la amplia extensión de la zona de riego.

Con toda la problemática expuesta, las actitudes de los grupos afectados han sido manifestaciones de inconformidad y demandas poco articuladas. En general son prácticamente nulas las acciones colectivas en demanda de sus intereses. De manera que no se vislumbra la articulación regional de estrategias de mejora de sus condiciones como productores en la cuenca, ni por medio de sus organizaciones, y tampoco desde las 
instituciones gubernamentales, como podría ser el diseño y establecimiento de mecanismos de ordenamiento y gestión integral del agua que regulen las condiciones de acceso en el ámbito local, distribución con equidad, optimización en su uso, reúso y saneamiento del agua; donde se involucren todos los actores: usuarios, organizaciones civiles, gobiernos locales y empresarios.

En estas condiciones, en la ciénega de Chapala michoacana, la disminución de la calidad del agua y los problemas entre usuarios por el acceso a la misma seguirán avanzando y profundizando el deterioro ecológico. Frente a esto, hay un escenario de vulnerabilidad socioambiental y de las actividades primarias, como la agricultura y la pesca.

\section{Bibliografía}

Aboites, Luis (2002), "Notas sobre el optimismo mexicano y los vínculos entre geografía, ingeniería hidráulica y política (1926-1976)", en Patricia Ávila García (ed.), Agua, cultura y sociedad en México, El Colegio de Michoacán-Instituto Mexicano de Tecnología del Agua, México, pp. 185-198.

Ávila, Patricia (1999), "El valle Morelia-Queréndaro y el deterioro ambiental”, en Esteban Barragán, Frutos del Campo en Michoacán, El Colegio de Michoacán, México, pp. 171-193.

Ávila-García, Patricia (2002), "Agua, poder y conflicto urbano en una ciudad media", en Patricia Ávila García (ed.), Agua, cultura y sociedad en México, El Colegio de Michoacán-Instituto Mexicano de Tecnología del Agua, México, pp. 271-292.

Ávila Ricardo (2005), Sistema para el estudio de la degradación ambiental de la cuenca Lerma-Chapala y su impacto en la zona metropolitana de Guadalajara en relación con el uso del suelo, proyecto de investigación, Universidad de Guadalajara.

Ayla-Jay, Jennifer y Tim Ford (2001), "Weater concentrations, bioaccumulacion, an Human Health Implications of Heavy Metals in Lake Chapala", en The Lerma-Chapala evaluation and management Watershed, Academic Publishers, Nueva York.

Barragán, María del Carmen, Ana Wagner, Cipriana Hernández y Alberto Güitrón (2004), Análisis comparativo de políticas de asignación del agua superficial en la cuenca Lerma-Chapala utili- 
zando el modelo dinámico de simulación "Lerma", Instituto Mexicano del Agua, <http:www.congresous.es/ciberico/archivos_word/215d.doc>, 20 de septiembre de 2007.

Boehm, Brigitte (2001), "El lago de Chapala, su ribera norte. Un ensayo de lectura del paisaje cultural”, Relaciones, XXII (85), El Colegio de Michoacán, México pp. 57-84.

Boehm, Brigitte (2005), "Citadinos y campesinos en el Consejo de Cuenca Directiva”, en Juan Manuel Durán Juárez et al. (coords.), Los estudios del agua en la cuenca Lerma-Chapala-Santiago II, El Colegio de Michoacán-Universidad de Guadalajara, México, pp. $15-54$.

Boehm, Brigitte (coord.) (2002), Cartografía histórica del lago de Chapala (versión en CD), El Colegio de Michoacán-Universidad de Guadalajara, México.

Burton, Tony (1997), “¿Se podrá salvar el mayor lago de México?: un esfuerzo internacional de rehabilitación viene en camino", Ecodecisión, 23, México, <http://www.mexconnect.com/es/ articles/3109-lake-chapala-can-mexico-s-largest-lake-be-saved>, 24 de mayo de 2009.

Caire-Martínez, Georgina (2005), "Conflictos por el agua en la cuenca Lerma-Chapala, 1996-2002”, Región y Sociedad, xvII (34), El Colegio de Sonora, Hermosillo, <lanic.utexas.edu/project/etext/ colson/34/3.pdf>, 15 de agosto de 2008 .

Conagua (Comisión Nacional del Agua) (2002), Determinación de la disponibilidad de agua en el acuifero ciénega de Chapala, estado de Jalisco, Conagua, México.

Conagua (Comisión Nacional del Agua) (2003), Programa Hidráulico Regional 2002-2006, Conagua, México.

Conagua (Comisión Nacional del Agua) (2005), Plan director para la modernización integral del riego en el Distrito de Riego 024 Ciénega Chapala, Conagua, México.

Conagua (Comisión Nacional del Agua) (2008), Estadisticas del agua en México, Semarnat, México. 
Conapo (Consejo Nacional de Población) (2000), Estimaciones con base en la muestra del diez por ciento del XII Censo General de Población y Vivienda 2000, Conapo, México.

Consejo de Cuenca Lerma-Chapala (2008), Boletín, Conagua, México, p. 2.

Covarrubias-Villa, Francisco, María Guadalupe Cruz Navarro y Alejandra Ojeda (2008), "El paisaje prehispánico de la ciénaga de Chapala", Tecsistecatl, 1 (4), <http://www.eumed.net/rev/tecsistecatl/n4/vns. htm>, 24 de mayo de 2009.

Durán-Juárez, Juan Manuel, Brigitte Boehm Schoendube, Martín Sánchez Rodríguez y Alicia Torres Rodríguez (coords.) (2005), Los estudios del agua en la cuenca Lerma-Chapala-Santiago II, El Colegio de Michoacán-Universidad de Guadalajara, México.

FAO (Food and Agriculture Organization) (1997), Lucha contra la contaminación agrícola de los recursos hidricos, GEMs Water Collaborating Centre-Canada Centre for Inland Waters, Burlington.

Frers, Cristian (2005), Los problemas de las aguas contaminadas, <http:// www.ecoportal.net/content/view/full/47049>, 2 de junio de 2009.

Gómez-Reyna, Antonio (2007), Chapala y su conflictiva ambiental, ponencia presentada en Participación del municipio en la conservación, protección, aprovechamiento y restauración del lago de Chapala, Chapala, Jal., 9 de marzo.

Guzmán-Arroyo, Manuel, Salvador Peniche Camps y Andrés Valdés Zepeda (2001), La cuenca del río Lerma y el lago de Chapala, <http://www.pvemjalisco.org.mx/principal/biblioteca/chapala/ files/01_LERMA.PDF>, 2 de junio de 2009.

Hansen, Anne y Manfred van Afferden (2001), "Toxic substances. Sources, Accumulation and Dynamics", en A. Hansen y M. van Afferden (eds.), The Lerma-Chapala evaluation and management Watershed, Academic Publishers, Nueva York.

Hernández-García, Adriana (2000), "El pueblo de Mezcala y sus efectos en la degradación del lago de Chapala", tesis de maestría, Centro 
de Investigaciones y Estudios Superiores en Antropología Social, Occidente, México.

INEGI (Instituto Nacional de Estadística, Geografía e Informática) (2000), XII Censo General de Población y Vivienda, INEGI, México.

INEGI (Instituto Nacional de Estadística, Geografía e Informática) (2004), Censos Económicos, INEGI, México.

INEGI (Instituto Nacional de Estadística, Geografía e Informática) (2005), II Conteo de Población y Vivienda, INEGI, México.

Mantilla-Morales, Gabriela, Héctor Sanvicente Chávez y Jorge Izurieta Dávila (2000), Identificación de las zonas de contaminación de los cuerpos de agua de la cuenca del río Lerma mediante la interpretación de imágenes de satélite y ubicación de las principales descargas de aguas residuales, Federación Mexicana de Ingeniería Sanitaria y Ciencias Ambientales-AIDIs, México.

Moreno-García, Heriberto (1988), Geografía y paisaje de la antigua ciénega de Chapala, Instituto Michoacano de Cultura, México.

Moreno-García, Heriberto (1989), Haciendas de tierra y agua, El Colegio de Michoacán, México.

Ochoa-Serrano, Álvaro (2003), Jiquilpan-Huanimban. Una historia confinada, Instituto Michoacano de Cultura-Morevallado Editores, México.

Oms (Organización Mundial de la Salud) (2006), Guias para la calidad del agua potable, vol. 1, oмs, México.

Paré, Luisa (1989), Los pescadores de Chapala y la defensa de su lago, Universidad Nacional Autónoma de México-Instituto Tecnológico y Estudios Superiores de Occidente-El Colegio de Jalisco, México.

Peña, Francisco (2005), "El saneamiento de la cuenca Lerma-Chapala. ¿Nudos tecnológicos o baches financieros?, en Juan Manuel Durán Juárez et al. (coords.), Los estudios del agua en la cuenca LermaChapala-Santiago II, El Colegio de Michoacán-Universidad de Guadalajara, México, pp. 135-144. 
Pimentel, David, Thomas W. Cullinery y T. Bashore (1996), Riesgos de salud pública asociados con pesticidas y toxinas naturales en alimentos, University of Minessota, Michigan.

PNUD (Programa de las Naciones Unidas para el desarrollo) (2008), Informe sobre desarrollo humano Michoacán 2007, PNUD, México.

Sedue (Secretaría de Desarrollo Urbano y Ecología) (1989), Acuerdo por el que se establecen los Criterios Ecológicos de Calidad del Agua ceccaA-001/89, Diario Oficial de la Federación, 13 de diciembre, México.

Semarnat (Secretaría de Medio Ambiente y Recursos Naturales) (2006), Acuerdo por el que se da a conocer el estudio técnico de los recursos hídricos del área geográfica Lerma-Chapala, <www.cna.

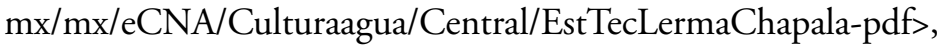
11 de octubre de 2007.

Silva-García, José Teodoro, Salvador Ochoa y Francisco Estrada Godoy (2006), Calidad química del agua subterránea de la ciénega de Chapala como factor de degradación del suelo, Instituto Politécnico Nacional, México.

Sotelo, Esthela, Nayeli Cardona, Alejandra Fregoso, Carlos Enríquez, Arturo Garrido, Georgina Caire y Helena Cotler (2005), Acciones estratégicas para la recuperación de la cuenca Lerma-Chapala: Recomendaciones técnicas para las diecinueve subcuencas, Instituto Nacional de Ecología, México.

Sugiura-Yamamoto, Yoko, José Alberto Anaya Aguirre, Magdalena Amalia García-Sánchez, Edgar Carro y Sandra Figueroa (1998), La caza, la pesca y la recolección: etnoarquelogía del modo de subsistencia lacustre en las ciénegas del Alto Lerma, Universidad Nacional Autónoma de México, México.

Tortajada, Cecilia (2002), "Abastecimiento de agua y manejo de descargas residuales en México: un análisis de las políticas ambientales”, en Patricia Ávila García (ed.), Agua, cultura y sociedad en México, El Colegio de Michoacán-Instituto Mexicano de Tecnología del Agua, México. 
Tortolero, Alejandro (2002), "El agua en la cuenca de México: usos e importancia del agua en la región de Chalco durante el siglo XIx", en Patricia Ávila García (ed.), Agua, cultura y sociedad en México, El Colegio de Michoacán-Instituto Mexicano de Tecnología del Agua, México.

Valdez-Zepeda, Andrés y Manuel Arroyo Guzmán (2000), El lago de Chapala. Una visión general, Universidad de Guadalajara, México.

Valdez-Zepeda, Andrés, Manuel Arroyo Gúzman y Salvador Peniche (2000), Chapala en crisis. Análisis de su problemática en el marco de la gestión pública y la sustentabilidad, Universidad de Guadalajara, México.

Zárate-del Valle, Pedro Fausto, Eduardo Mendizábal y Nely Ríos (2009), "Evaluación biológica y geoquímica de la interfaz sedimento-agua del lago de Chapala", informe de investigación, Universidad de Guadalajara, México.

\section{Entrevistas}

Arceo, Enrique, acuicultor de Venustiano Carranza, realizada el 18 de junio de 2008.

Guillén, Francisco, gerente técnico del módulo de riego "Ballesteros, realizada el 18 de octubre de 2007.

Víctor, Gerardo, ejidatario de Sahuayo, realizada el 22 de enero de 2010.

Víctor, Jesús, pescador de Petatán, realizada el 8 de abril de 2008.

Recibido: 26 de junio de 2009.

Reenviado: 28 de enero de 2010.

Aceptado: 9 de febrero de 2010.

Adriana Sandoval-Moreno. Es doctora en ciencias sociales; maestra en estudios regionales, y licenciada en sociología. Es investigadora de tiempo completo en la UnAm, Unidad Académica de Estudios Regionales sede Jiquilpan, Michoacán, donde es responsable de la investigación Estudio de las repercusiones y estrategias de los grupos locales en el manejo de los recursos hídricos en la cuenca Chapala, y su contexto social, económico 
y ambiental, de agosto de 2006 a la fecha. Actualmente es coordinadora general del proyecto Recuperación integral de la microcuenca del río Jiquilpan a la dinámica social, proyecto de investigación interinstitucional la UNAM y el ayuntamiento de Jiquilpan, Michoacán, con la colaboración del Centro de Investigación Interdisciplinario para el Desarrollo Integral Regional-Politécnico. Es candidata a investigadora del Sistema Nacional de Investigadores (sNI). Ha sido consultora en temas de participación social y género para la Deutsche Gesellschaft für Technische Zusammenarbeit (GTZ), de 2003 a 2008. Entre sus publicaciones recientes destacan: en coautoría, Plan de manejo de la cuenca del río Lerma en el valle de Toluca. Informe final, Conagua-Agencia Técnica de Cooperación Alemania (GTz)-Rodeco Consulting GMBH, México (2008); "Organización y acceso al agua entre regantes de la ciénega de Chapala, Michoacán”, en Adriana Sandoval Moreno (coord.), Sociedad y culturas regionales. Problemas locales, miradas globales, UNAM (en prensa); "Acción colectiva en el manejo de agua en la ciénega de Chapala, Michoacán”, en Carlos Téllez Valencia y Magdalena García Sánchez (coords.), Estudios michoacanos, vol. XIII, El Colegio de Michoacán, México.

María Antonieta Ochoa-Ocaña. Es licenciada en nutrición; maestra en antropología física y candidata a doctora en antropología, los tres grados por la Universidad Nacional Autónoma de México (UNAM). Tiene un diplomado en antropología médica. Es investigadora de tiempo completo en la Unidad Académica de Estudios Regionales de la Coordinación de Humanidades de la unam, sede Jiquilpan, Michoacán, donde es responsable del proyecto Ambiente, salud y nutrición. Un acercamiento a la calidad de vida de la región de la ciénega del lago de Chapala. Sus publicaciones recientes son: Los preescolares de Maltrata, Ver. Una visión desde la antropología nutricional, unAM, México (2006); "Calidad de vida en la ciénega", en Sociedad y culturas regionales. Problemas locales, miradas globales, UnAM, México (en prensa); Sabores y saberes de la ciénega michoacana. Recetario, unam-Universidad del Claustro de Sor Juana, México (en dictamen). 